\section{OPEN ACCESS}

Edited by:

Esmaeil Mortaz,

National Research Institute of

Tuberculosis and Lung Diseases

(NRITLD), Iran

Reviewed by:

Gunnar N. Hillerdal,

Karolinska University

Hospital, Sweden

Le Thuong Vu,

Ho Chi Minh City Medicine and

Pharmacy University, Vietnam

Rossana Berardi,

Marche Polytechnic University, Italy

${ }^{*}$ Correspondence:

László Bajnok

bajnok.laszlo@pte.hu

Specialty section:

This article was submitted to

Pulmonary Medicine,

a section of the journal

Frontiers in Medicine

Received: 24 February 2021

Accepted: 29 October 2021

Published: 07 December 2021

Citation:

Bartalis E, Gergics M, Tinusz B, Földi $M$, Kiss $S$, Németh $D$,

Solymár M, Szakács Z, Hegyi P,

Mezösi E and Bajnok L (2021)

Prevalence and Prognostic

Significance of Hyponatremia in

Patients With Lung Cancer:

Systematic Review and

Meta-Analysis. Front. Med. 8:671951.

doi: 10.3389/fmed.2021.671951

\title{
Prevalence and Prognostic Significance of Hyponatremia in Patients With Lung Cancer: Systematic Review and Meta-Analysis
}

\begin{abstract}
Eszter Bartalis ${ }^{1,2}$, Marin Gergics ${ }^{3}$, Benedek Tinusz ${ }^{1,4}$, Mária Földi ${ }^{1,4,5}$, Szabolcs Kiss ${ }^{1,4,5}$, Dávid Németh ${ }^{1,4}$, Margit Solymár ${ }^{1,4}$, Zsolt Szakács ${ }^{1,4}$, Péter Hegyi ${ }^{1,4}$, Emese Mezösi ${ }^{3}$ and László Bajnok ${ }^{3 *}$
\end{abstract}

${ }^{1}$ Medical School, Institute for Translational Medicine, University of Pécs, Pécs, Hungary, ${ }^{2}$ University of Medicine, Pharmacy, Science and Technology of Târgu Mureș, Târgu Mureş, Romania, ${ }^{3}$ First Department of Medicine, Medical School, University of Pécs, Pécs, Hungary, ${ }^{4}$ Szentágothai Research Centre, University of Pécs, Pécs, Hungary, ${ }^{5}$ Doctoral School of Clinical Medicine, University of Szeged, Szeged, Hungary

Background: The prevalence of hyponatremia is highly variable among patients with lung cancer. However, its prevalence and prognostic significance in subgroups of patients with lung cancer have not yet been evaluated in a meta-analysis.

Methods: We have registered our meta-analysis and review protocol to the PROSPERO International Prospective Register of Systematic Reviews, with the following registration number: CRD42020167013. A systematic search was done in the following sources: MEDLINE, Embase, CENTRAL, Web of Science, ClinicalTrials.gov, a WHO Global Health Library.

Results: We identified a total of 8,962 potentially eligible studies, and we included 31 articles in our evaluation. The prevalence of hyponatremia in patients with lung cancer varied between 3 and $94.8 \%$ with an average of 25\% without any significant differences between the following subgroups: histotype, gender, age, Eastern Cooperative Oncology Group (ECOG) state, and the extent of disease. The overall survival (OS) was significantly lower in hyponatremic compared to normonatremic patients at 10 months [RR.59 (95\% Cl.47-0.74), $p<0.001$ ] and at 20 months [RR.44 (95\% Cl.33-0.59), $p<0.001$ ], with worse survival rates in non-small cell lung cancer (NSCLC) [RR.27 (95\% Cl.12-0.44), $p$ $<0.001$ ] than in small cell lung cancer (SCLC) [RR.42 (95\% Cl.27-0.57), $p<0.001$ ]. If hyponatremia was corrected, OS at 10 months was significantly higher than in the uncorrected hyponatremia group [RR 1.83 (95\% Cl 1.37-2.44), $p<0.001$ ], but, at 20 months, no statistically significant difference could be found between these subgroups [RR 2.65 (95\% Cl.94-7.50), $p=0.067$ ].

Conclusions: Patients with lung cancer diagnosed with hyponatremia, especially patients with NSCLC, seem to have significantly lower survival rates than normonatremic patients. If hyponatremia remains uncorrected, the mortality rates might be even higher.

Keywords: lung cancer, NSCLC, SCLC, hyponatremia, SIADH 


\section{BACKGROUND}

Lung cancer is one of the most frequent malignancies worldwide in both sexes, and $75 \%$ of patients are diagnosed at an advanced stage. According to the reports of the WHO in 2018, it is the leading cause of mortality among cancers (1). Moreover, based on the WHO's Global Cancer Observatory's report, the incidence of lung cancer is predicted to grow by $72.5 \%$ by 2040 (2).

The reported prevalence values of hyponatremia $(<$ $135 \mathrm{mmol} / \mathrm{L}$ ) among patients with lung cancer are highly discordant in the literature, varying between 3.7 and $75 \%$ (3-8). Although inappropriate antidiuretic hormone secretion (SIADH) is the most common underlying cause $(4,5)$, the prevalence of SIADH seems to be lower among patients with lung cancer compared to hyponatremia, varying from 9.1 to $39 \%$ in small cell lung cancer (SCLC) $(6,9-11)$ and $7-4 \%$ in non-small cell lung cancer (NSCLC) $(6,12)$. SIADH was diagnosed even less frequently in the general cancer population $(4,13,14)$. This discrepancy may be partially explained by insufficient diagnostic work-up and the presence of other comorbidities that also affect the sodium level (15-17).

Based on literature reports, hyponatremia and SIADH appear to be important negative prognostic factors of mortality in numerous medical conditions, including lung cancer $(4,9$, $12,18-22)$, but not every study reached this conclusion $(6,10)$. However, a recent meta-analysis of 15 studies confirmed the prognostic significance of serum sodium levels by demonstrating that the correction of hyponatremia is associated with a reduced risk of mortality in hospitalized patients with oncology (23).

Following a preliminary search of the literature, we found discordant results regarding the prevalence and prognostic significance of hyponatremia in patients with lung cancer, and the findings considerably differ from the studies and reviews cited above. This study aims to make a reappraisal of the occurrence and prognostic impact of pre and posttreatment (oncological, symptomatic, and supportive) hyponatremia, specifically in patients with lung cancer.

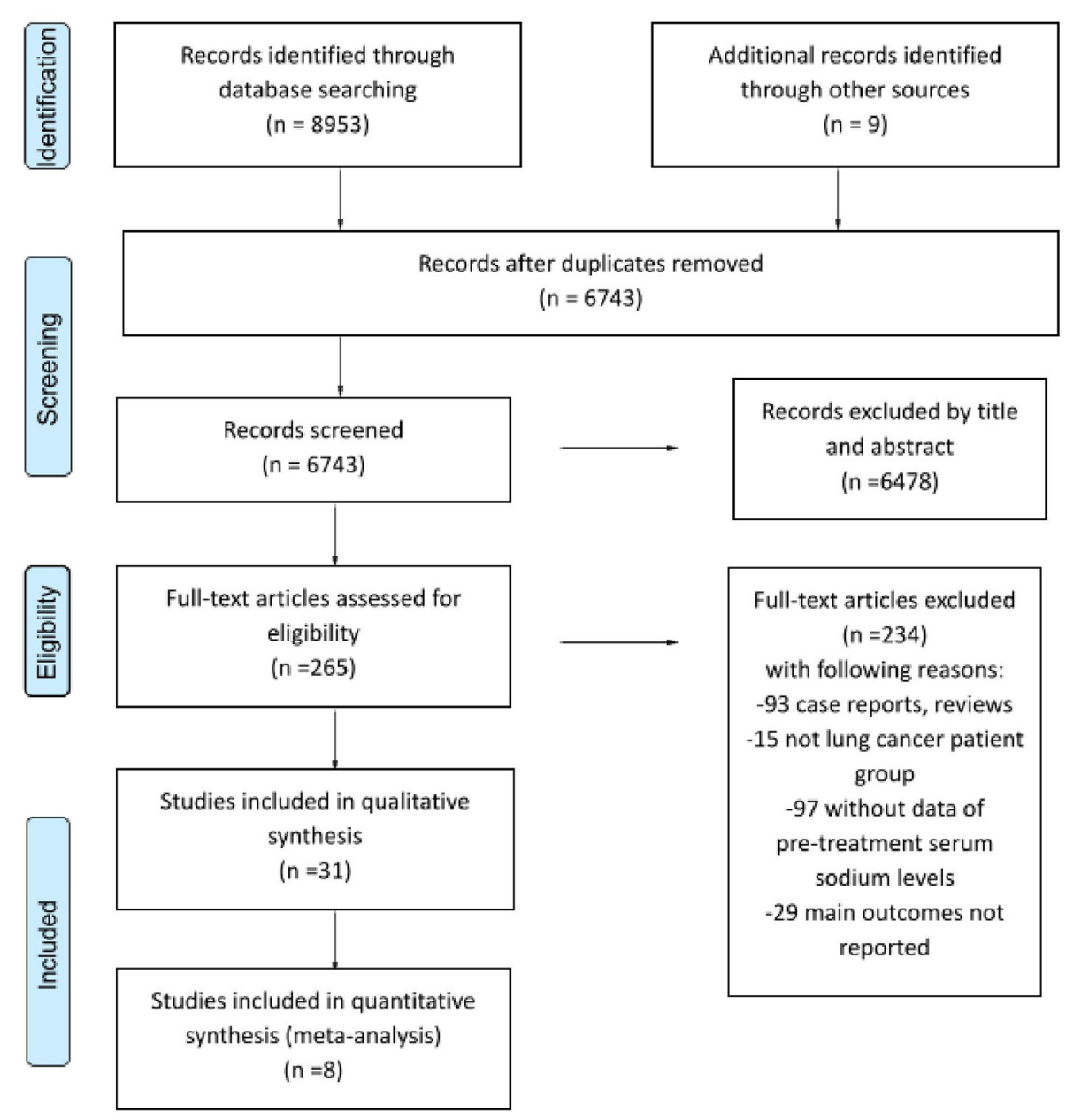

FIGURE 1 | A preferred reporting items for systematic reviews and meta-analyses (PRISMA) flow diagram representing the process of study search and selection. 
TABLE 1 | Characteristics of the included studies in the systematic review.

\begin{tabular}{|c|c|c|c|c|c|c|c|c|c|c|}
\hline Study & Country & Study design & $\begin{array}{c}\text { Nr. of } \\
\text { patients }\end{array}$ & Histotype & $\begin{array}{l}\text { Follow-up } \\
\text { time }\end{array}$ & Male N (\%) & $\begin{array}{l}\text { Age cut-off } \\
\text { (years) }\end{array}$ & $\begin{array}{l}\text { Older } \\
\mathrm{N}(\%)\end{array}$ & $\begin{array}{l}\text { Na level } \\
\text { cut-off } \\
\text { (mmol/L) }\end{array}$ & $\begin{array}{c}\text { Hyponatremia } \\
\quad N(\%)\end{array}$ \\
\hline Yang et al. (27) & China & Retrospective & 320 & SCLC & 40 weeks & 219 (68.4\%) & 60 & 222 (69.4\%) & 135 & 149 (46.6\%) \\
\hline Osterlind et al. (28) & Denmark & Retrospective & 815 & SCLC & 18-54 weeks & $584(71.7 \%)$ & 60 & $428(52.5 \%)$ & 136 & 204 (25.0\%) \\
\hline Zarzecka et al. (29) & Poland & Retrospective & 290 & NSCLC & NR & 205 (70.7\%) & $N R$ & NR & 135 & 47 (16.2\%) \\
\hline Hermes et al. (30) & Germany & Retrospective & 395 & SCLC & NR & $240(60.8 \%)$ & 60 & $260(65.8 \%)$ & 135 & 75 (19.0\%) \\
\hline Wang et al. (31) & China & Retrospective & 631 & SCLC & NR & 475 (75.3\%) & 65 & $91(14.4 \%)$ & 135 & 66 (10.5\%) \\
\hline Berardi et al. (32) & Italy & Retrospective & 433 & NSCLC & NR & 299 (69.1\%) & NR & NR & 135 & 69 (15.9\%) \\
\hline Sengupta et al. (33) & India & Retrospective & 116 & $\begin{array}{l}\text { NSCLC } \\
+ \text { SCLC }\end{array}$ & NR & $83(71.6 \%)$ & NR & NR & 135 & $\begin{array}{l}45 \text { (45.5\%) } \\
\quad 7(41.2 \%)\end{array}$ \\
\hline Kobayashi et al. (34) & Japan & Retrospective & 386 & NSCLC & 41.2 months & 259 (67.1\%) & $N R$ & NR & 139 & $123(31.9 \%)$ \\
\hline Fucá et al. (35) & Italy & Prospective & 197 & NSCLC & 25.7 months & $120(60.9 \%)$ & 65 & $113(57.4 \%)$ & 135 & $26(13.2 \%)$ \\
\hline Alamoudi (36) & Saudi Arabia & Prospective & 114 & $\begin{array}{l}\text { SCLC } \\
+\mathrm{NSCLC}\end{array}$ & NR & $89(78.1 \%)$ & NR & NR & 130 & $64(56.1 \%)$ \\
\hline Hansen et al. (37) & Denmark & Retrospective & 453 & SCLC & 60 months & $243(53.6 \%)$ & 60 & $323(71.3 \%)$ & 135 & 198 (44\%) \\
\hline Svaton et al. (38) & Czech Republic & Retrospective & 544 & NSCLC & 84 months & $343(63.1 \%)$ & 65 & 242 (44.5\%) & 136 & 117 (21.5\%) \\
\hline Allan et al. (39) & U.K. & Retrospective & 411 & SCLC & NR & NR & 65 & $120(29.2 \%)$ & 135 & $111(27.0 \%)$ \\
\hline Li et al. (40) & China & Retrospective & 1083 & NSCLC & 40.84 months & 757 (69.9\%) & 65 & 295 (27.2\%) & 141,9 & 165 (15.2\%) \\
\hline Osterlind et al. (41) & Denmark & Retrospective & 874 & SCLC & 18 months & $631(72.2 \%)$ & 60 & $450(51.5 \%)$ & 136 & $213(24.4 \%)$ \\
\hline Doshi et al. (42) & India & Retrospective & 257 & NSCLC & NR & 180 (70.0\%) & NR & NR & 136 & $120(46.7 \%)$ \\
\hline Johnson et al. (43) & U.S.A. & Prospective & 50 & $\begin{array}{l}\text { SCLC } \\
+ \text { NSCLC }\end{array}$ & NR & $33(66.0 \%)$ & $N R$ & NR & 130 & $\begin{array}{c}10 \text { (32.3\%) } \\
1(5.3 \%)\end{array}$ \\
\hline Sagman et al. (44) & Canada & Retrospective & 614 & SCLC & NR & 436 (71.0\%) & 70 & 88 (14.3\%) & 135 & 142 (23.1\%) \\
\hline Jacot et al. (45) & France & Retrospective & 301 & NSCLC & 20.8 months & 242 (80.4\%) & NR & NR & NR & $24(8.0 \%)$ \\
\hline Hong et al. (46) & China & Retrospective & 999 & SCLC & 10.6 months & $692(69.3 \%)$ & 60 & 387 (38.7\%) & 135 & $163(29.5 \%)$ \\
\hline Maestu et al. (47) & Spain & Retrospective & 341 & SCLC & NR & 336 (98.5\%) & 65 & $88(25.8 \%)$ & 135 & $10(3 \%)$ \\
\hline Kawahara et al. (48) & Japan & Retrospective & 286 & SCLC & NR & $233(81.5 \%)$ & 66 & $113(39.5 \%)$ & 136 & $40(14.0 \%)$ \\
\hline Cerny et al. (49) & U.K. & Retrospective & 407 & SCLC & NR & 262 (64.4\%) & NR & NR & 132 & $53(13.0 \%)$ \\
\hline Ma et al. (50) & China & Retrospective & 158 & SCLC & NR & 135 (85.4\%) & 60 & 61 (38.6\%) & 135 & $67(42.4 \%)$ \\
\hline Umemura et al. (51) & Japan & Retrospective & 163 & SCLC & 36 months & 129 (79.1\%) & 70 & $69(42.3 \%)$ & 135 & 22 (13.5\%) \\
\hline Jacot et al. (52) & France & Retrospective & 231 & NSCLC & 35 months & $194(84,0 \%)$ & 60 & $104(45 \%)$ & 132 & 219 (94.8\%) \\
\hline Rechnitzer et al. (53) & Germany & Prospective & 229 & NSCLC & 42 months & $185(80.8 \%)$ & 63 & $69(30.1 \%)$ & 137.5 & $59(25,8 \%)$ \\
\hline Bose et al. (54) & India & Retrospective & 40 & NSCLC & 6 months & 38 (95\%) & $N R$ & NR & 125 & $8(20 \%)$ \\
\hline Rinaldi et al. (55) & Italy and UK & Retrospective & 647 & NSCLC & NR & $440(68 \%)$ & 65 & NR & 135 & 105 (16.2\%) \\
\hline Chan et al. (56) & Ireland & Retrospective & 624 & LC & NR & 370 (59.3\%) & NR & NR & 135 & 197 (31.6\%) \\
\hline Huang et al. (57) & China & Retrospective & 358 & SCLC & NR & 286 (79.9\%) & 70 & 49 (13.7\%) & 137 & 54 (15.1\%) \\
\hline
\end{tabular}

SCLC, Small cell lung cancer; NSCLC, Non-small cell lung cancer; RCT, Randomized control trial; U.S.A, United States of America; U.K., United Kingdom; NR, Not reported. 
TABLE 2 | Different oncological treatment protocols in the included studies.

\begin{tabular}{|c|c|c|c|c|c|}
\hline \multirow{2}{*}{$\begin{array}{l}\text { Studies } \\
\text { Yang et al. (27) }\end{array}$} & \multicolumn{2}{|c|}{ Study interval } & \multirow{2}{*}{$\begin{array}{l}\text { Histotype } \\
\text { SCLC }\end{array}$} & \multirow{2}{*}{$\begin{array}{c}\begin{array}{c}\text { Number of } \\
\text { patients }\end{array} \\
320\end{array}$} & \multirow{2}{*}{$\begin{array}{l}\text { Oncological treatment protocols } \\
\mathrm{PB}+\mathrm{E}\end{array}$} \\
\hline & 2006 & 2012 & & & \\
\hline Zarzecka et al. (29) & 2010 & 2012 & NSCLC & 290 & NSCLC - PB and third generation drugs, in SCLC with PB+E \\
\hline Hermes et al. (30) & 2004 & 2008 & SCLC & 395 & $\mathrm{~PB}+\mathrm{E}$ \\
\hline Berardi et al. (32) & 2006 & 2015 & NSCLC & 433 & PB, Non-PB, EGFR- TKI \\
\hline Sengupta et al. (33) & 2011 & 2012 & NSCLC & 116 & unknown \\
\hline Kobayashi et al. (34) & 2000 & 2009 & NSCLC & 386 & resection+ postoperative adjuvant treatment \\
\hline Fucá et al. (35) & 2013 & 2018 & NSCLC & 197 & PD-1/PDL-1 inhibitors \\
\hline Alamoudi (36) & 2004 & 2008 & LC & 114 & unkown \\
\hline Osterlind et al. (41) & 1973 & 1981 & SCLC & 874 & $\mathrm{~L}+\mathrm{C}+\mathrm{M}, \mathrm{L}+\mathrm{C}+\mathrm{M}+\mathrm{V}, \mathrm{L}+\mathrm{C}+\mathrm{M}+\mathrm{V}+\mathrm{D}+\mathrm{E},+/$ - radiotherapy \\
\hline Doshi et al. (42) & 2010 & 2014 & NSCLC & 257 & $\mathrm{~PB}+\mathrm{PM}$ \\
\hline Johnson et al. (43) & 1989 & 1992 & LC & 50 & $\mathrm{~PB}+\mathrm{E}$ \\
\hline Sagman et al. (44) & 1976 & 1986 & SCLC & 614 & Different protocols: $\mathrm{C}+\mathrm{D}+\mathrm{V}, \mathrm{L}+\mathrm{P}+\mathrm{M}, \mathrm{PB}+\mathrm{E}$ \\
\hline Jacot et al. (45) & 2003 & 2006 & NSCLC & 301 & surgery, PB, second line, palliative \\
\hline Hong et al. (46) & 2000 & 2009 & SCLC & 999 & chemotherapy(etoposide)+/-radiotherapy+/-surgery \\
\hline Maestu et al. (47) & 1981 & 1993 & SCLC & 341 & different protocols: $\mathrm{C}+\mathrm{D}+\mathrm{V}, \mathrm{PB}$ and others+/- radio \\
\hline Kawahara et al. (48) & 1985 & 1988 & SCLC & 286 & different protocols: $C+D+V, P+E$, or $C+D+V+P+E$ \\
\hline Cerny et al. (49) & 1979 & 1985 & SCLC & 407 & different protocols: $\mathrm{C}+\mathrm{M}+\mathrm{E}+$ /-radiotherapy \\
\hline Ma et al. (50) & 2000 & 2007 & SCLC & 158 & unknown \\
\hline
\end{tabular}

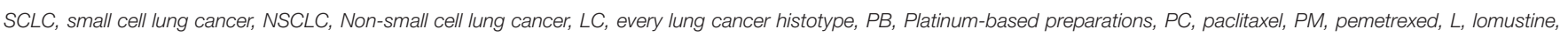

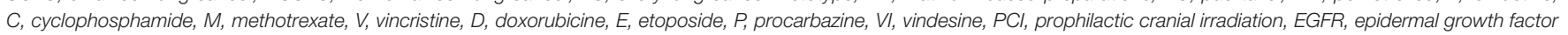
receptor, TKI, tyrosine kinase inhibitors.

\section{METHODS}

\section{Protocol and Registration}

We report this systematic review and meta-analysis according to the preferred reporting items for systematic reviews and meta-analyses (PRISMA, 2009) Statement (24) described in Supplementary File 1. We have registered our meta-analysis and review protocol to the PROSPERO International Prospective Register of Systematic Reviews, with the following registration number: CRD42020167013. There were no deviations from the study protocol.

\section{Search Strategy}

The first step was to create a PECO (patient-exposure/prognostic factor-comparison-outcome): "P," patients with lung cancer; "E," hyponatremia at the time of the diagnosis/before treatment; "C," normonatremia at the time of the diagnosis/before treatment; "O," overall survival time and the rate at 10 and 20 months. Then, we created a search key based on our PECO, which included search terms related to the group of the patients and the prognostic factor: (lung cancer OR SCLC OR NSCLC OR carcinoid) AND (SIADH OR the sodium level OR the Na level OR hyponatremia OR hyponatremia $O R$ syndrome of inappropriate ADH OR antidiuretic hormone OR hypotonicity).

We searched the following sources: MEDLINE (via PubMed), Embase, Cochrane Central Register of Controlled Trials (CENTRAL), Web of Science, ClinicalTrials.gov, and WHO Global Health Library. The "human" filter was applied in the case of MEDLINE, Embase, and the WHO Global Health Library. The "trials" and "completed" filters were utilized when searching 
TABLE 3A | The outcomes in lung cancer patients among the included studies.

\begin{tabular}{|c|c|c|c|c|c|c|c|c|c|c|}
\hline Study & \multicolumn{2}{|c|}{ Median OS times } & $p$-value & \multicolumn{2}{|c|}{ Survival rates, mortality } & $p$-value & \multicolumn{4}{|c|}{ Multivariate analysis } \\
\hline Osterlind et al. (28) & NR & NR & - & $N R$ & NR & - & NR & - & - & - \\
\hline Wang et al. (31) & 14.5 months & 11.4 months & $<0.001$ & $N R$ & NR & - & I & 1.82 & $1.34-2.47$ & 0.007 \\
\hline Berardi et al. (32) & 15.5 months & 8.78 months & $<0.001$ & $57.06 \%$ SR & $33.33 \% \mathrm{SR}$ & 0.19 & 1 & 1.59 & $1.14-2.21$ & 0.006 \\
\hline Sengupta et al. (33) & NR & NR & - & $N R$ & NR & - & $\mathrm{NI}$ & - & - & NS \\
\hline Kobayashi et al. (34) & $N R$ & NR & - & 74.8\% 5-year SR & $59.7 \%$ 5-year SR & 0.002 & 1 & 1.53 & $1.01-2.32$ & 0.047 \\
\hline Svaton et al. (38) & 10.9 months & 4.6 months & $<0.001$ & $\begin{array}{l}54.33 \% \text { SR at } 10 \\
\text { months }\end{array}$ & $\begin{array}{l}21.36 \% \text { SR at } 10 \\
\text { months }\end{array}$ & $<0.001$ & 1 & 1.87 & $1.47-2.39$ & $<0.001$ \\
\hline
\end{tabular}

OS, overall survival; NN, normonatremic; HN, hyponatremic; NR, Not reported; S-significant; NS, not significant; I, Independent factor; N.I., Not independent factor; HR, hazard ratio; $R R$, risk ratio; $S R$, Survival rate; $C l$, confidence interval; $L D$, Limited Disease; $E D$, Extensive Disease.

TABLE 3B | The outcomes in lung cancer patients among the included studies.

\begin{tabular}{|c|c|c|c|c|c|c|c|c|c|c|}
\hline \multirow[t]{2}{*}{ Study } & \multicolumn{2}{|c|}{ Median OS times } & \multirow[t]{2}{*}{$p$-value } & \multicolumn{2}{|c|}{ Survival rates, mortality } & \multirow[t]{2}{*}{$p$-value } & \multicolumn{4}{|c|}{ Outcome in multivariate analysis } \\
\hline & NN patients & HN patients & & NN patients & HN patients & & & HR & $95 \% \mathrm{Cl}$ & $p$-value \\
\hline Allan et al. (39) & 7 months & 7 months & 0.06 & NR & NR & - & $\mathrm{NI}$ & - & - & NS \\
\hline Li et al. (40) & NR & NR & - & $79.6 \%$ SR at 25 months & $73.83 \%$ SR at 25 months & - & NR & - & - & - \\
\hline Osterlind et al. (41) & 40 weeks & 34 weeks & - & NR & NR & - & I & - & - & $<0.05$ \\
\hline Doshi et al. (42) & 16 months & 11 months & $<0.05$ & $\begin{array}{l}61.31 \% \text { SR at } 10 \\
\text { months }\end{array}$ & $54.16 \%$ SR at 10 months & - & I & 2.07 & $1.11-3.84$ & $<0.05$ \\
\hline Johnson et al. (43) & $N R$ & NR & - & NR & NR & - & $\mathrm{Nl}$ & - & - & NS \\
\hline Sagman et al. (44) & 45 weeks & 42 weeks & 0.006 & NR & NR & - & $\mathrm{Nl}$ & - & - & NS \\
\hline Jacot et al. (45) & 18.7 months & 4.1 months & $<0.0001$ & NR & NR & - & 1 & 1.99 & $1.04-3.77$ & S \\
\hline Hong et al. (46) & 11.7 months & 10 months & 0.039 & $\begin{array}{l}59.48 \% \text { SR at } 10 \\
\text { months }\end{array}$ & $49.69 \%$ SR at 10 months & - & $\mathrm{Nl}$ & - & - & NS \\
\hline Maestu et al. (47) & NR & NR & - & NR & NR & - & $\mathrm{Nl}$ & - & - & NS \\
\hline Kawahara et al. (48) & 11.4 months & 9.1 months & 0.0072 & NR & NR & - & $\mathrm{NI}$ & - & - & NS \\
\hline Cerny et al. (49) & NR & NR & - & $\begin{array}{l}59.48 \% \text { SR at } 10 \\
\text { months }\end{array}$ & $34 \%$ SR at 10 months & - & 1 & - & - & 0.0009 \\
\hline Ma et al. (50) & 14.1 months & 7.6 months & $<0.001$ & $\begin{array}{l}81.31 \% \text { SR at } 10 \\
\text { months }\end{array}$ & $32.83 \%$ SR at 10 months & - & NR & - & - & - \\
\hline Umemura et al. (51) & 10.6 months & 10 months & 0.6653 & $50 \%$ SR at 10 months & $51.77 \%$ SR at 10 months & NS & $\mathrm{Nl}$ & - & - & NS \\
\hline Jacot et al. (52) & 7.5 months & 3.85 months & 0.0141 & NR & NR & - & I & 2.99 & $1.17-7.62$ & 0.022 \\
\hline Rechnitzer et al. (53) & 6.7 months & 3 months & $<0.001$ & NR & NR & - & I & - & - & $<0.001$ \\
\hline Bose et al. (54) & NR & NR & $<0.03$ & NR & NR & - & NR & - & - & - \\
\hline Rinaldi et al. (55) & 15.3 months & 10.3 months & 0.003 & NR & NR & - & I & 1.29 & $1.03-1.54$ & 0.047 \\
\hline Chan et al. (56) & NR & NR & - & NR & NR & - & NR & - & - & - \\
\hline Huang et al. (57) & 14.5 months & 11 months & 0.008 & NR & NR & - & 1 & 1.49 & $1.04-2.13$ & 0.03 \\
\hline
\end{tabular}

OS, overall survival; NN, normonatremic; HN, hyponatremic; NR, Not reported; S-significant; NS, not significant; I, Independent factor; NI, Not independent factor; HR, hazard ratio; RR, risk ratio; SR, Survival rate; $\mathrm{Cl}$, confidence interval. 
TABLE 4 | Risk of bias assessment.

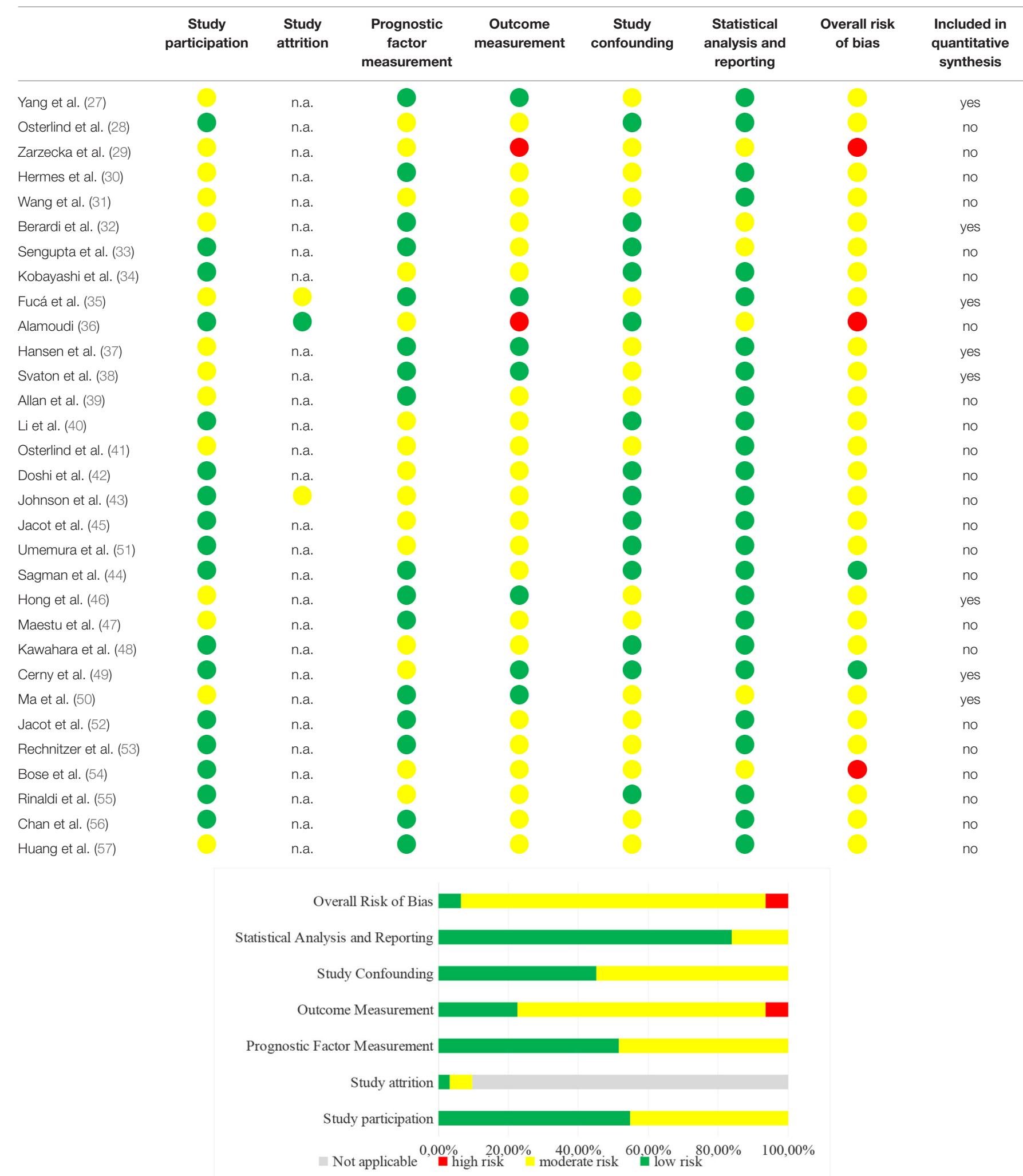

[CHART] 
TABLE 5 | Results of the statistical analyses.

\begin{tabular}{|c|c|c|c|c|c|}
\hline \multicolumn{6}{|c|}{ Prevalence of hyponatremia } \\
\hline Subgroups & $\mathbf{R R}$ & $95 \% \mathrm{Cl}$ & $P$ value & Heterogeneity $\left(I^{\wedge} 2\right)$ & $\begin{array}{c}P \text { value of } \\
\text { heterogeneity }\end{array}$ \\
\hline SCLC & 0.24 & {$[0.18 ; 0.30]$} & $\begin{array}{c}\text { NS } \\
p=0.425\end{array}$ & $96.56 \%$ & $\begin{array}{l}<0.001 \\
<0.001\end{array}$ \\
\hline NSCLC & 0.27 & {$[0.17 ; 0.39]$} & & $98.57 \%$ & \\
\hline male vs. female & 1.15 & {$[0.86 ; 1.53]$} & $\begin{array}{c}\text { NS } \\
p=0.354\end{array}$ & $75.40 \%$ & $<0.001$ \\
\hline$<60$ years vs. $\geq 60$ years & 0.97 & {$[0.80 ; 1.19]$} & $\begin{array}{c}\text { NS } \\
p=0.773\end{array}$ & $0.00 \%$ & 0.657 \\
\hline$E C O G \leq 1$ vs. $E C O G>1$ & 0.80 & {$[0.59 ; 1.09]$} & $\begin{array}{c}\text { NS } \\
p=0.161\end{array}$ & $70.10 \%$ & 0.001 \\
\hline LD vs. ED stage & 1.17 & {$[0.60 ; 2.28]$} & $\begin{array}{c}\text { NS } \\
p=0.655\end{array}$ & $87.8 \%$ & $<0.001$ \\
\hline \multicolumn{6}{|l|}{ Overall survival rates } \\
\hline \multicolumn{6}{|c|}{ Hyponatremic vs. Normonatremic patients: } \\
\hline 10 months & 0.59 & {$[0.47 ; 0.74]$} & $<0.001$ & $81.1 \%$ & $<0.001$ \\
\hline 20 months & 0.44 & {$[0.33 ; 0.59]$} & $<0.001$ & $40.5 \%$ & 0.109 \\
\hline \multicolumn{6}{|c|}{ Hyponatremic SCLC vs. NSCLC patients at 10 months: } \\
\hline SCLC & 0.42 & {$[0.27 ; 0.57]$} & $<0.001$ & $92.72 \%$ & $<0.001$ \\
\hline NSCLC & 0.27 & {$[0.12 ; 0.44]$} & $<0.001$ & - & - \\
\hline \multicolumn{6}{|c|}{ Corrected vs. Uncorrected hyponatremic patients: } \\
\hline 10 months & 1.83 & {$[1.37 ; 2.44]$} & $<0.001$ & $0.0 \%$ & 0.775 \\
\hline 20 months & 2.65 & {$[0.94 ; 7.50]$} & 0.067 & $23.3 \%$ & 0.271 \\
\hline
\end{tabular}

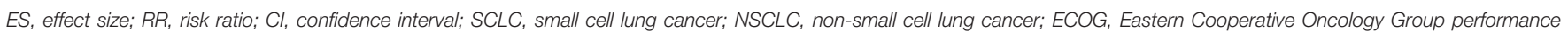
status; $L D$, limited disease; $E D$, extensive disease.

in the Cochrane Library or ClinicalTrials.gov, respectively. We did not apply any language or date restriction to our search. We also performed a search on the bibliography of the eligible articles. The date of the search was 12.03.2019. Then, we updated our systematic search with the same search strategy used before on 05.07.2021.

\section{Eligibility and Exclusion Criteria}

Studies qualified our systematic review after fulfilling the following requirements: (1) observational or interventional cohort studies, case-control studies, randomized-controlled trials, and case series. Besides full-text articles, conference abstracts were also eligible for inclusion; (2) trials enrolling adult patients (18 years or above) with lung cancer with available information of characteristics of patients with lung cancer (number of patients, age, sex, histological type of cancer, extent of disease, and performance status) and pretreatment serum sodium levels; (3) trials reporting data on overall survival (OS) time and the rate at 10 and 20 months, or with available information about multivariate analysis of the prognostic significance of hyponatremia.

The exclusion criteria were the following: (1) case studies, case reports, reviews, comments, and letters; (2) studies investigating other lung pathologies or solid cancers; (3) lack of data on serum sodium levels before treatment; (4) papers not reporting outcomes mentioned before.

\section{Study Selection and Data Extraction}

After the initial search, all records from each database were imported into a reference management program (EndNote X7, Clarivate Analytics, Philadelphia, PA, USA). This software was used to remove duplicates. After the removal of duplicates, the authors screened the remaining articles against the predefined eligibility criteria first by title, abstract, and then full text. Two researchers conducted each step independently, and any disagreements were resolved by consensus.

Numerical data were extracted by two independent investigators, any disagreements were resolved by consensus, and data were manually entered on an Excel 2018 sheet (Office 365, Microsoft, Redmond, WA, USA). These were collected on the first author, year of publication, study design, geographical location, number of patients, and basic demographics (age and sex ratio), in each group. Additional information on the histological type of the tumor, disease extent, Eastern Cooperative Oncology Group (ECOG) Performance status, the grade of hyponatremia, and the length of follow-up was also obtained. We also collected information about hyponatremia improvement that was achieved by oncologic, symptomatic, and/or supportive treatment, including at least two cycles of chemotherapy, sodium supplementation, or fluid restriction.

\section{Outcomes}

Finally, data were collected on the primary and secondary outcomes of interest, such as the prevalence of hyponatremia, 


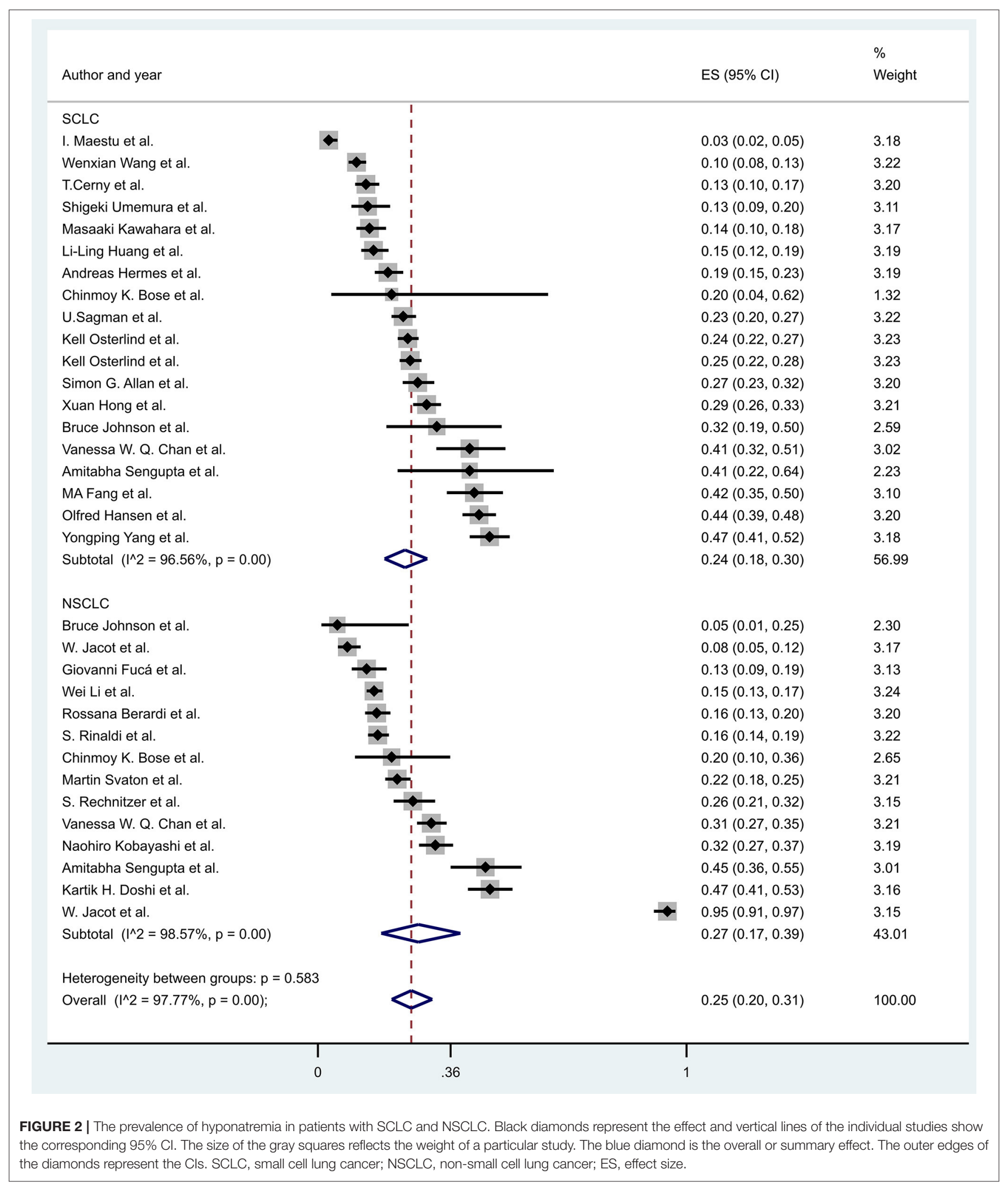

median OS time, and the OS rate at 10 and 20 months of patients with normonatremia and hyponatremia and results of multivariate analyses of lung cancer patients with hyponatremia.

\section{Risk of Bias Assessment}

We used the Quality in Prognostic Studies (QUIPS) tool (25) for assessing the risk of bias, which is 


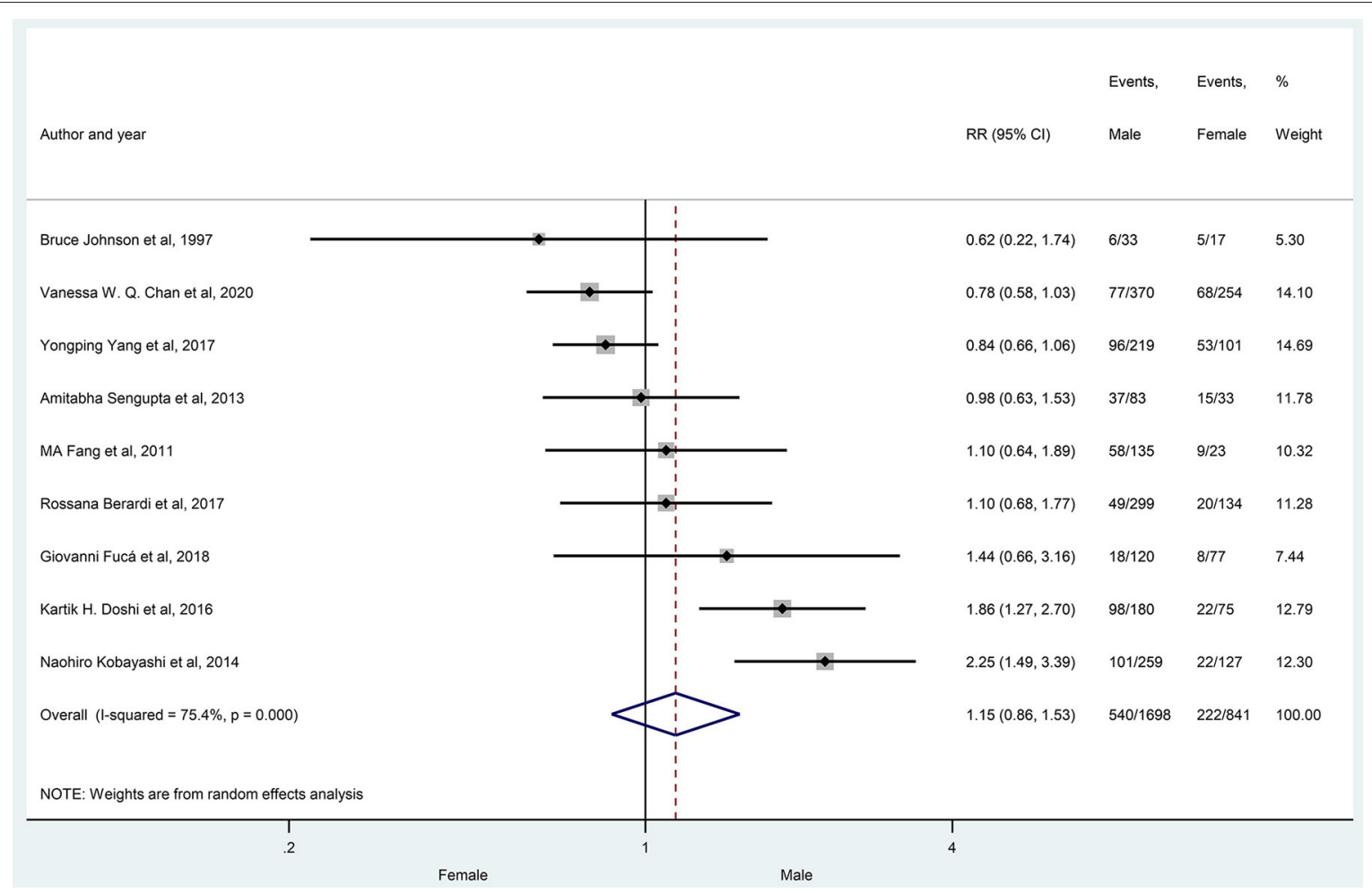

FIGURE 3 | The prevalence of hyponatremia in male and female patients with lung cancer. Black diamonds represent the individual effects of studies, and vertical lines show the corresponding $95 \% \mathrm{Cl}$. The size of the gray squares reflects the individual weight of a particular study. The blue diamond shows the overall or summary effect. The outer edges of the diamonds represent the Cls. RR, risk ratio.

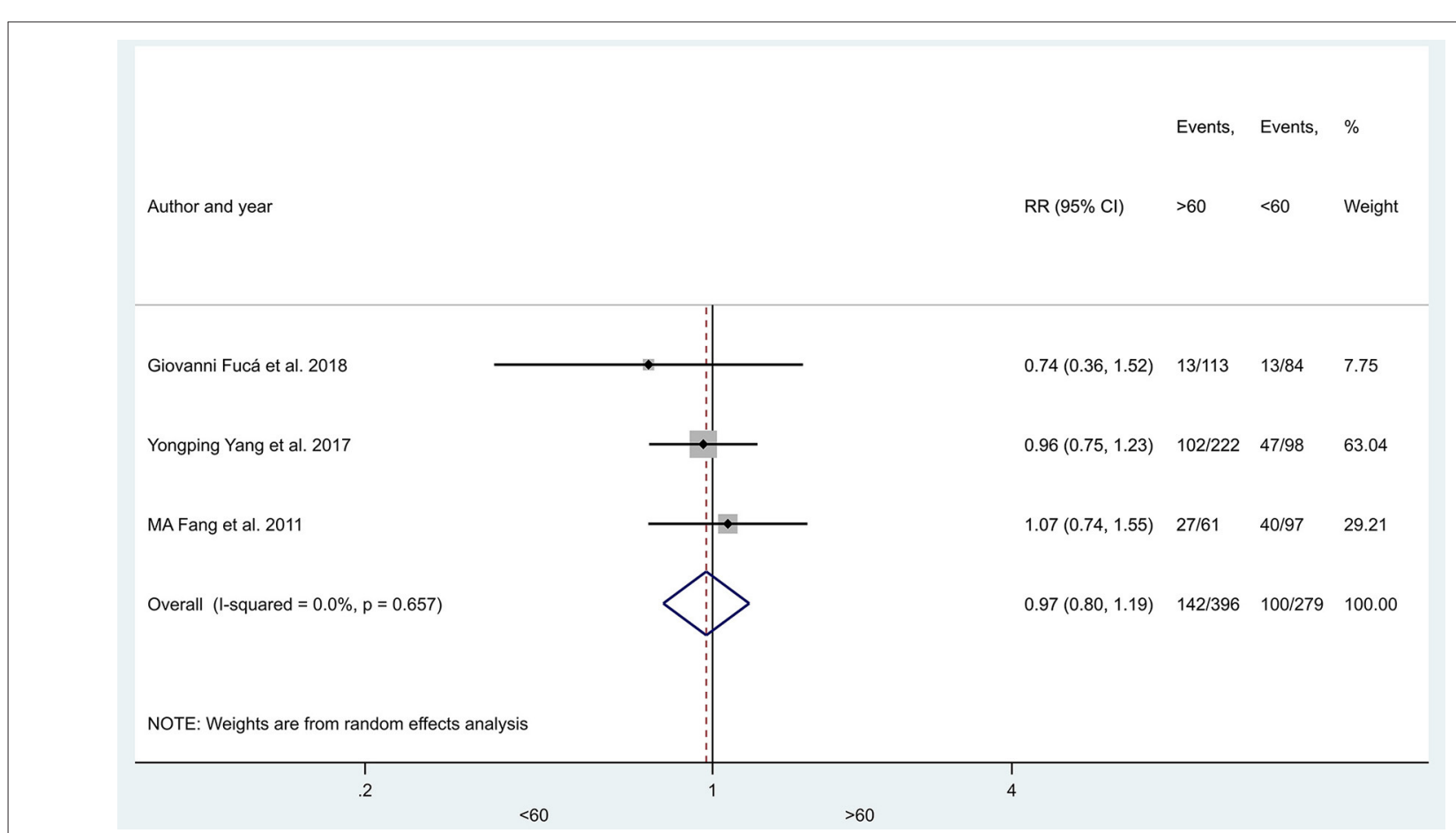

FIGURE 4 | The prevalence of hyponatremia in young (<60 years) and older patients (> 60 years) with lung cancer. Black diamonds represent the individual effects of studies, and vertical lines show the corresponding $95 \% \mathrm{Cl}$. The size of the gray squares reflects the individual weight of a particular study. The blue diamond shows the overall or summary effect. The outer edges of the diamonds represent the Cls. RR, risk ratio. 
described in Supplementary File 2. Any disagreements between the two independent researchers were solved by consensus.

\section{Statistical Analysis}

The effect measure of dichotomous variables was reported for each outcome as the relative risk (RR) with the related 95\% CI. All tests were two-sided, and $p<0.05$ was considered statistically significant (except for heterogeneity, for which a $p<0.10$ was considered significant). The random-effects model was used because of the minor differences between individual studies.

Heterogeneity was tested by performing both Cochran's Q test and calculating Higgins' $\mathrm{I}^{\wedge} 2$ indicator. $p<0.10$ was considered suggestive of significant heterogeneity. The I2 index corresponds to the percentage of the total variability across studies, which is due to heterogeneity. Based on the Cochrane Handbook for Systematic Reviews of Interventions (26), a rough classification of its value is the following: low (0-40\%), moderate (30-60\%), substantial (50-90\%), and considerable (75$100 \%)$. All the statistical analyses were performed using Stata IC (version 15.1).

\section{RESULTS}

The selection process is summarized in Figure 1. We identified a total of 8,962 potentially eligible studies in the literature, 1,858 articles in MEDLINE, 5,201 articles in Embase, 315 records in CENTRAL, 1,440 articles in Web of Science, 33 in ClinicalTrials.gov, and 115 in WHO Global Health Library. After screening by title, abstract, and full text, we chose 31 studies for our evaluation based on our eligibility criteria. Since not all studies reported on every parameter, we could include only a limited number of studies in each sub-analysis.

\section{Systematic Review}

The characteristics of the studies are summarized in a table included in Table 1. All selected reports were published in peer-reviewed journals, including four prospective and 27 retrospective cohort or case-control studies. The number of participants in the trials varied from 40 to 1,083 patients. Every selected article reported demographic information of the investigated population and data on the serum sodium levels at admission or before starting oncological treatment. In all of the 31 articles selected, we analyzed the prevalence

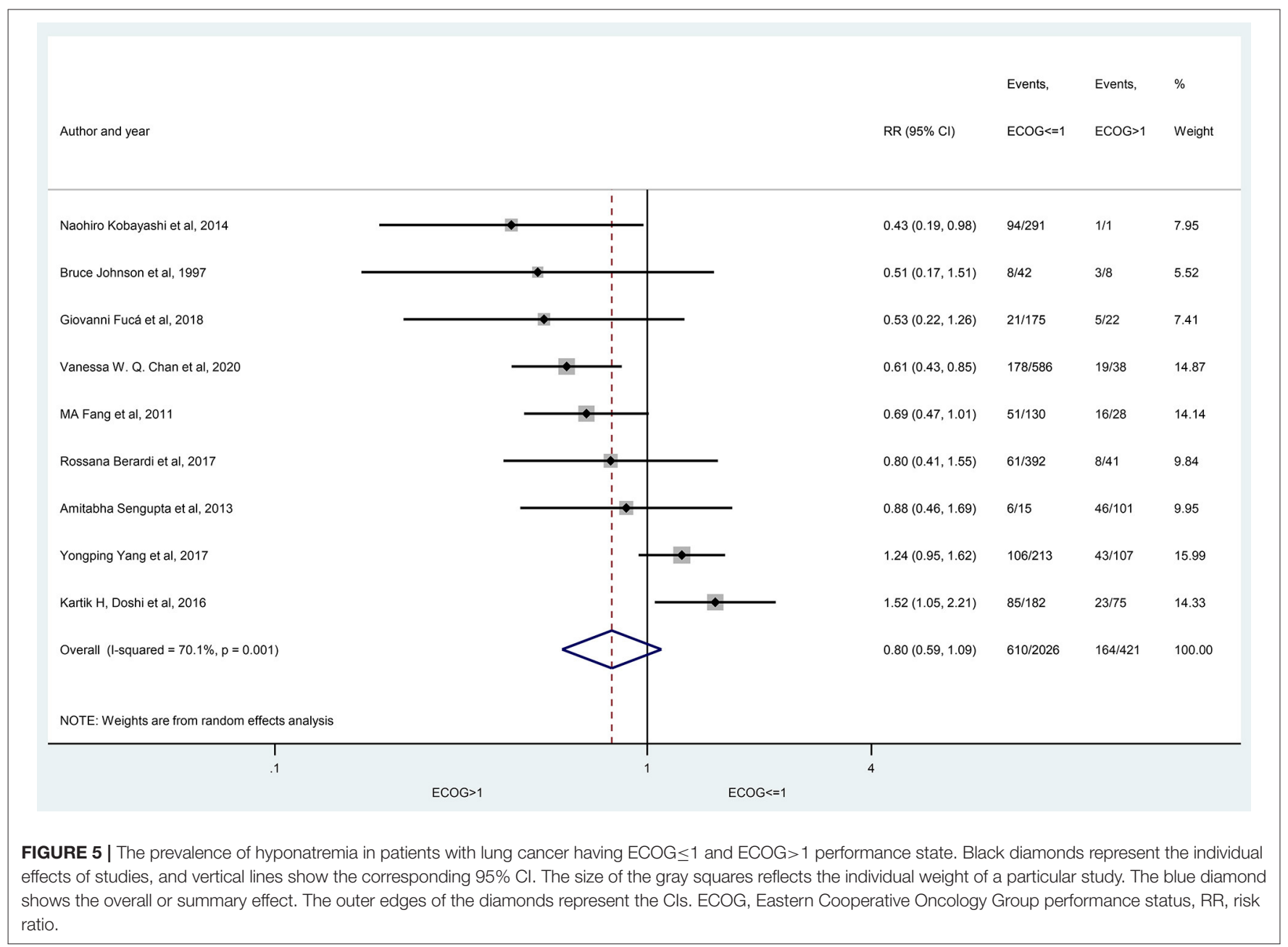




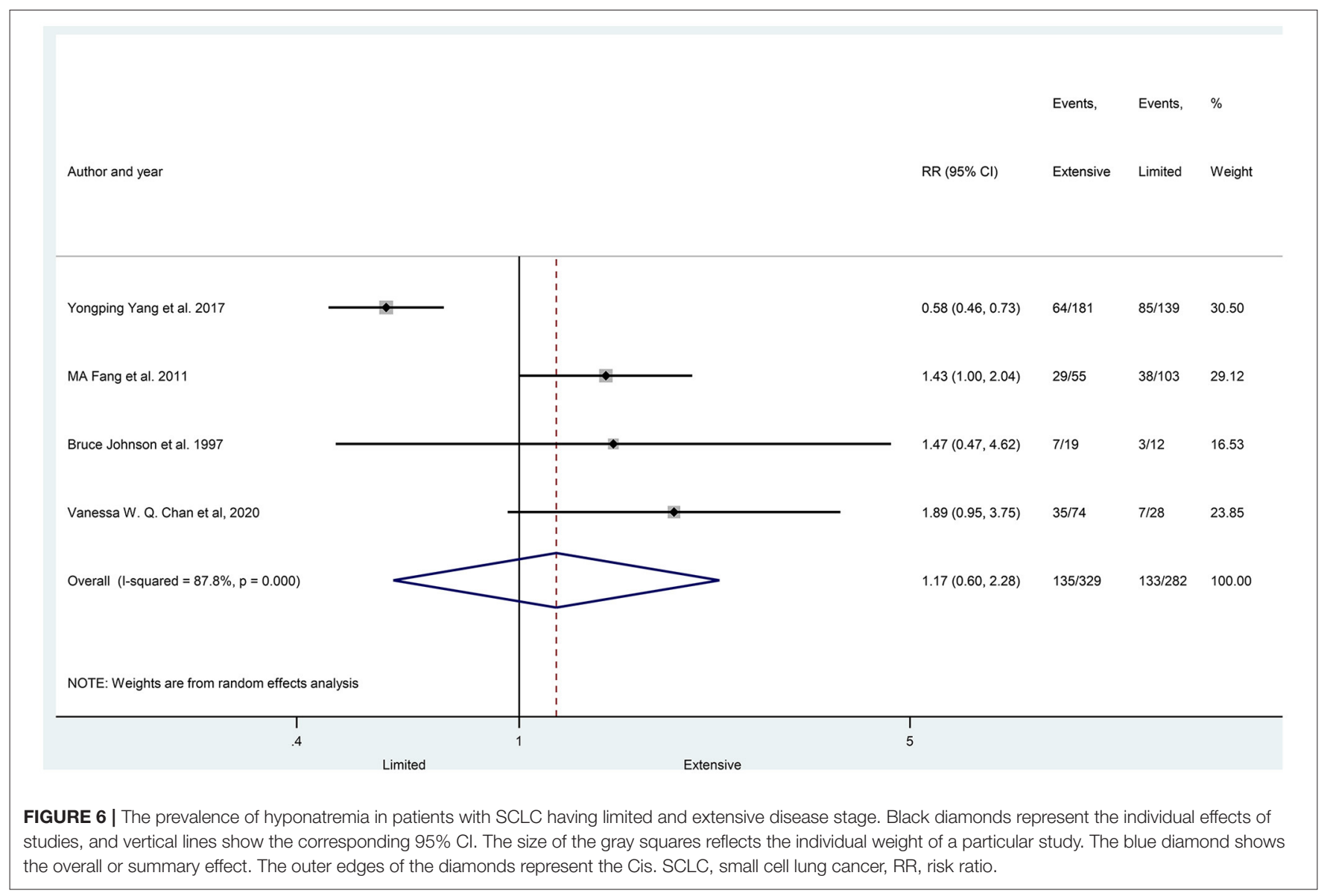

of hyponatremia. However, the analysis of the prognostic significance was performed only in 26 studies due to the lack of data in some articles. Furthermore, only 15 studies reported on median OS times, and the OS rates at 10 and 20 months were available in even fewer studies $(n=8)$.

The main clinical characteristics of patients in individual articles are shown in Tables 1, 2). Out of the 12,767 patients included, $57.8 \%(N=7,379)$ were diagnosed with SCLC, $41.2 \%$ $(N=5,255)$ with NSCLC, $65 \%(8,298)$ were men and $27.3 \%$ were women. The reported median age ranged from 49 to 68 years. With a cut-off value of 60 years (eight studies), $52.6 \%$ of the studied population was older than 60 years, while, with a cut-off value of 65 years (seven studies), $70.4 \%$ was younger. In total, 2,973 patients had hyponatremia at admission or before starting oncological treatment. The applied cut-off values varied between 132 and $139 \mathrm{mmol} / \mathrm{L}$ across studies. Hyponatremia was diagnosed in 1,499 of 6,792 patients (22.1\%) using a $135 \mathrm{mmol} / \mathrm{L}$ cut-off value in most of the included articles (16 studies), while, in five studies, where the cut-off value was $136 \mathrm{mmol} / \mathrm{L}$, the number of patients with hyponatremia was 694 out of 2,776 patients (25\%). In most cases, the oncological treatment for SCLC consisted of platinum-based preparations and etoposide, and, for NSCLC, were platinum-based preparations and/or surgery (Table 2).
The results of various outcomes among the selected studies are shown in Table 3. The prognostic significance of hyponatremia was evaluated in 26 studies and was found to be an independent prognostic factor in 15 studies, whereas, in eight studies, it was not.

After evaluating the risk of bias in each study using the QUIPS tool, the included reports had a low, high, and most medium risk of bias (Table 4).

\section{Meta-Analysis}

The summary of the results of the statistical analysis is presented in Table 5.

The prevalence of hyponatremia in patients with lung cancer varied between 3 and $94.8 \%$ (3-46.6\% in SCLC and 5.3-94.8\% in NSCLC) with an average of 25\% (24\% SCLC and 27\% NSCLC) in the evaluated reports without significant differences between patients with SCLC vs. patients with NSCLC (29 articles, $p=$ 0.425) (Figure 2), or in the subgroups created by the following criteria: gender (nine articles, $p=0.354$ ), age (three articles, $p=$ 0.773 ), ECOG state (nine articles, $p=0.161$ ), the extent of disease (four articles, $p=0.655$ ) (Figures 3-6).

The meta-analysis of the overall survival rates of lung cancer patients with hyponatremia was performed on eight selected studies (median follow-up time, 40 months), and a subgroup 


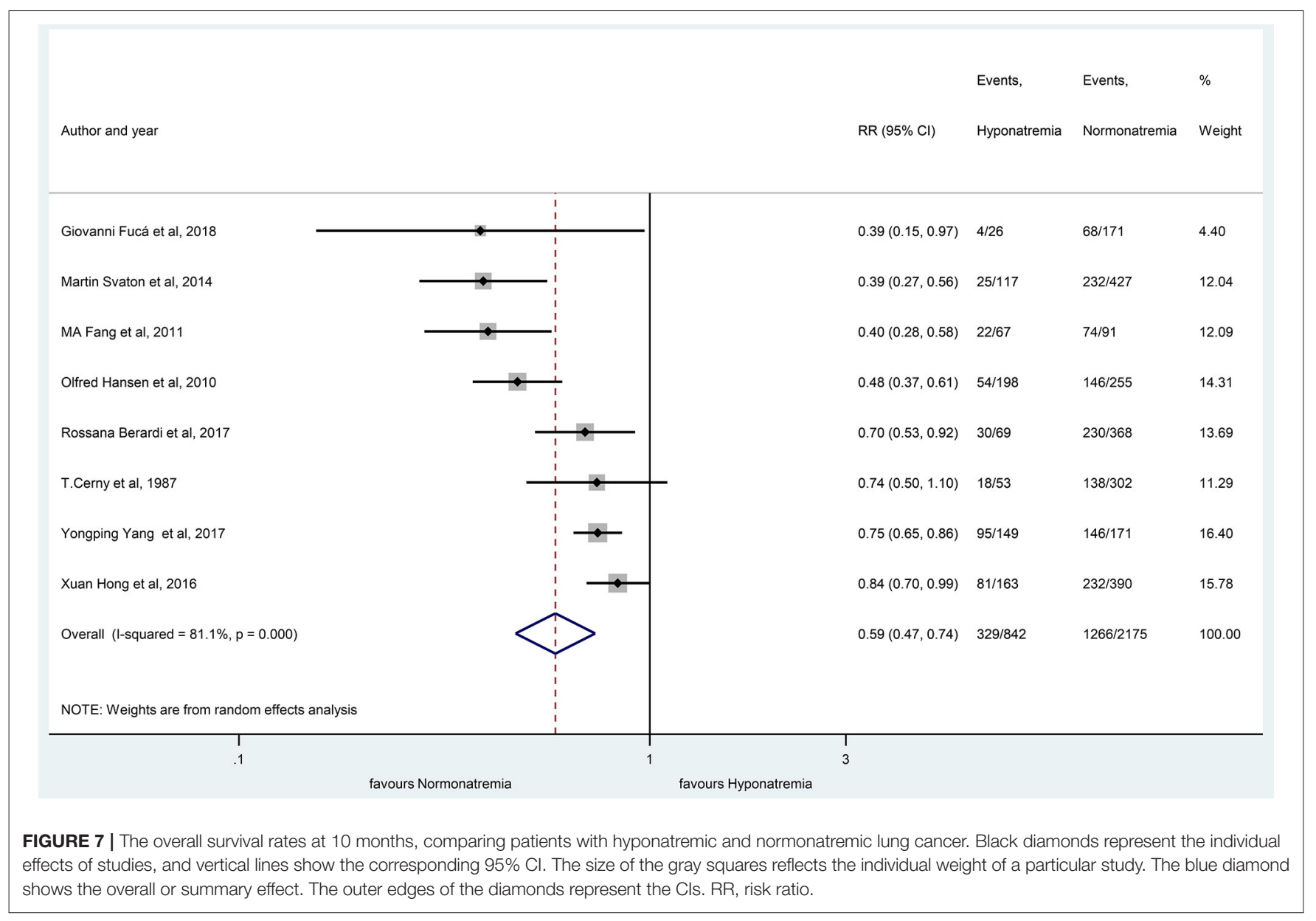

analysis was also carried out, comparing patients with SCLC and NSCLC.

The patients with hyponatremia, in comparison to patients with normonatremia, had significantly lower OS at 10 months (RR, 0.59 with $95 \%$ CI:0.47-0.74, $p<0.001$ ) and 20 months (RR, 0.44 with $95 \%$ CI:0.33-0.59, $p<0.001)$, respectively, as shown in Figures $7,8$.

You can see in Figure 9 that there was a lower overall survival rate at 10 months in patients with hyponatremic NSCLC (RR, 0.27, with 95\% CI:0.12-0.44, $p<0.001$ ) compared to patients with hyponatremic SCLC (RR, 0.42, with 95\% CI:0.27$0.57, p<0.001)$. However, no direct statistical comparison was performed.

Information about the improvement of overall survival rates, following the correction of hyponatremia, was available in only four studies. In the selected articles, the changes in serum sodium levels were the result of oncologic, symptomatic, or supportive treatment, including at least two cycles of chemotherapy, sodium supplementation, or fluid restriction. After the correction of hyponatremia, the overall survival rates at 10 months were significantly higher when compared with the uncorrected hyponatremia group (RR, 1.83 with 95\% CI: 1.37-2.44, $p<0.001$ ) (Figure 10).
However, at 20 months, no significant differences were identified between these groups (RR, 2.65 with 95\% CI:0.95-7.50, $p=0.067)$, as shown in Figure 11.

\section{DISCUSSION}

Regarding the prevalence of hyponatremia in patients with lung cancer, discordant results have been published. In 1 review, the incidence of hyponatremia was suggested to be in the range of $15-75 \%$ among patients with lung cancer (3). At the same time, in another one, the prevalence varied in a lower range, from 5 to $36 \%$, with an average of $15 \%$ in SCLC, and $4-2 \%$ in NSCLC (6). In other reviews, the prevalence of hyponatremia and/or SIADH was even less: Grohe et al. found hyponatremia in $14 \%$ of patients with SCLC and 2.7\% of NSCLC (7), while Christoforos Efthymiou et al. showed that SIADH was present in $7-16 \%$ of patients with SCLC and was rare among patients with NSCLC (1\%) (8).

To the best of our knowledge, ours is the first article which is not only a systematic review but also a meta-analysis evaluating the prevalence of hyponatremia in patients with lung cancer. According to our systematic search for the studies available in the literature, the prevalence of hyponatremia varies between 


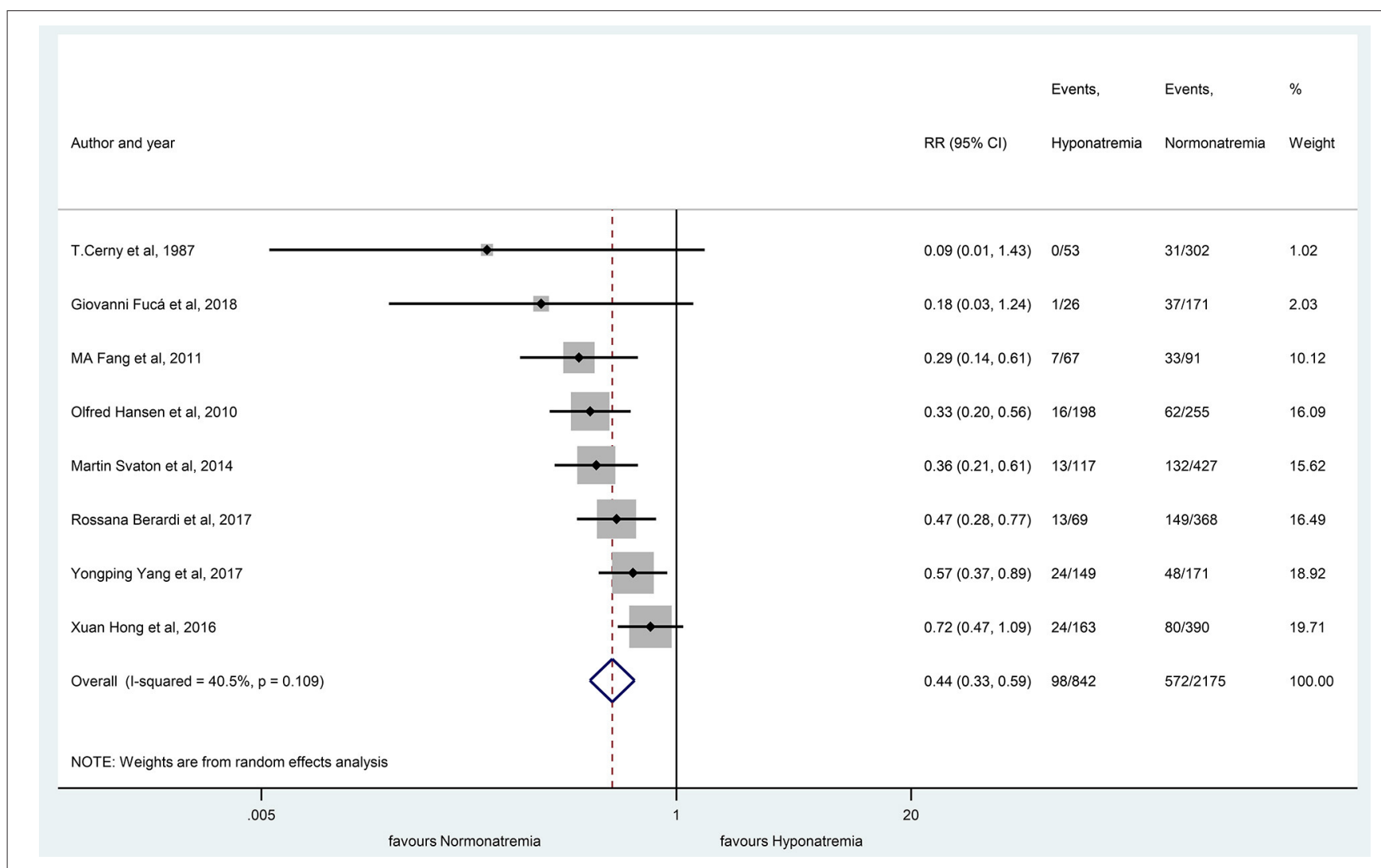

FIGURE 8 | The overall survival rates at 20 months, comparing patients with hyponatremic and normonatremic lung cancer. Black diamonds represent the individual effects of studies, and vertical lines show the corresponding $95 \% \mathrm{Cl}$. The size of the gray squares reflects the individual weight of a particular study. The blue diamond shows the overall or summary effect. The outer edges of the diamonds represent the Cls. RR, risk ratio.

3. and $94.8 \%$, with a pooled prevalence of $25 \%$ in patients with lung cancer. However, contrary to the general concept, our comprehensive evaluation and statistical analyses showed no significant difference in the prevalence of hyponatremia between SCLC and NSCLC (24 vs. $27 \%$ pooled mean frequency). The prevalence of hyponatremia has not differed significantly in the other subgroups either. So, in contrast to reviews $(58,59)$ and studies about the general hospitalized populations $(60,61)$, in patients with lung cancer, the presence of hyponatremia is not associated with age or gender. In respect of ECOG performance status or disease extent, ours is the first meta-analysis to describe that the prevalence of hyponatremia is independent of these parameters in lung cancer. Furthermore, ethnicity seems to be an important factor as well. In the article of K. Doshi and colleagues, ethnicity has been reported to be a risk factor in hyponatremia, but, unfortunately, we did not have enough data to analyze this aspect; therefore, more ethnicity-focused studies are needed (42).

The differences in the reported frequency values of low serum sodium levels in the cited reviews may be caused by the lack of appropriate studies; different eligibility criteria (hyponatremia at admission or during hospitalization); various patient groups (general hospitalized, general cancer, or only patients with SCLC/NSCLC and other subgroups); and different cut-off values (130-136 mmol/L).
Hyponatremia has an overall negative impact on mortality (5, 62-64). In a meta-analysis carried out in various hyponatremic patient groups, a significant association was revealed between hyponatremia and overall mortality (20). However, the 1,47,948 patients with hyponatremia included (from 81 studies) were not only subjects with different solid tumors but also patients with other medical conditions, such as myocardial infarction, heart failure, liver cirrhosis, and pulmonary infections. In a prospective study of patients with cancer, the mortality was higher among the patients with hyponatremic cancer compared to the whole cancer population (19.5 vs. 6.3\%) (5). In a systematic review analyzing the prognostic role of hyponatremia in malignancies, including lung cancer, it was found to be a negative prognostic factor (19). In lung cancer, many authors also identified hyponatremia as an independent negative risk factor $(30,32,34,35)$. At the same time, Umemura and colleagues found that vasopressin (AVP) is a better prognostic factor than sodium levels (51). In another systematic review, the causes, diagnosis, management, and the role of hyponatremia were evaluated among patients with lung cancer. They concluded that hyponatremia is a negative prognostic and predictive factor. Furthermore, they highlighted the importance of assessing the serum sodium levels of patients with lung cancer to improve their quality of life (12). We could confirm that hyponatremia is significantly 


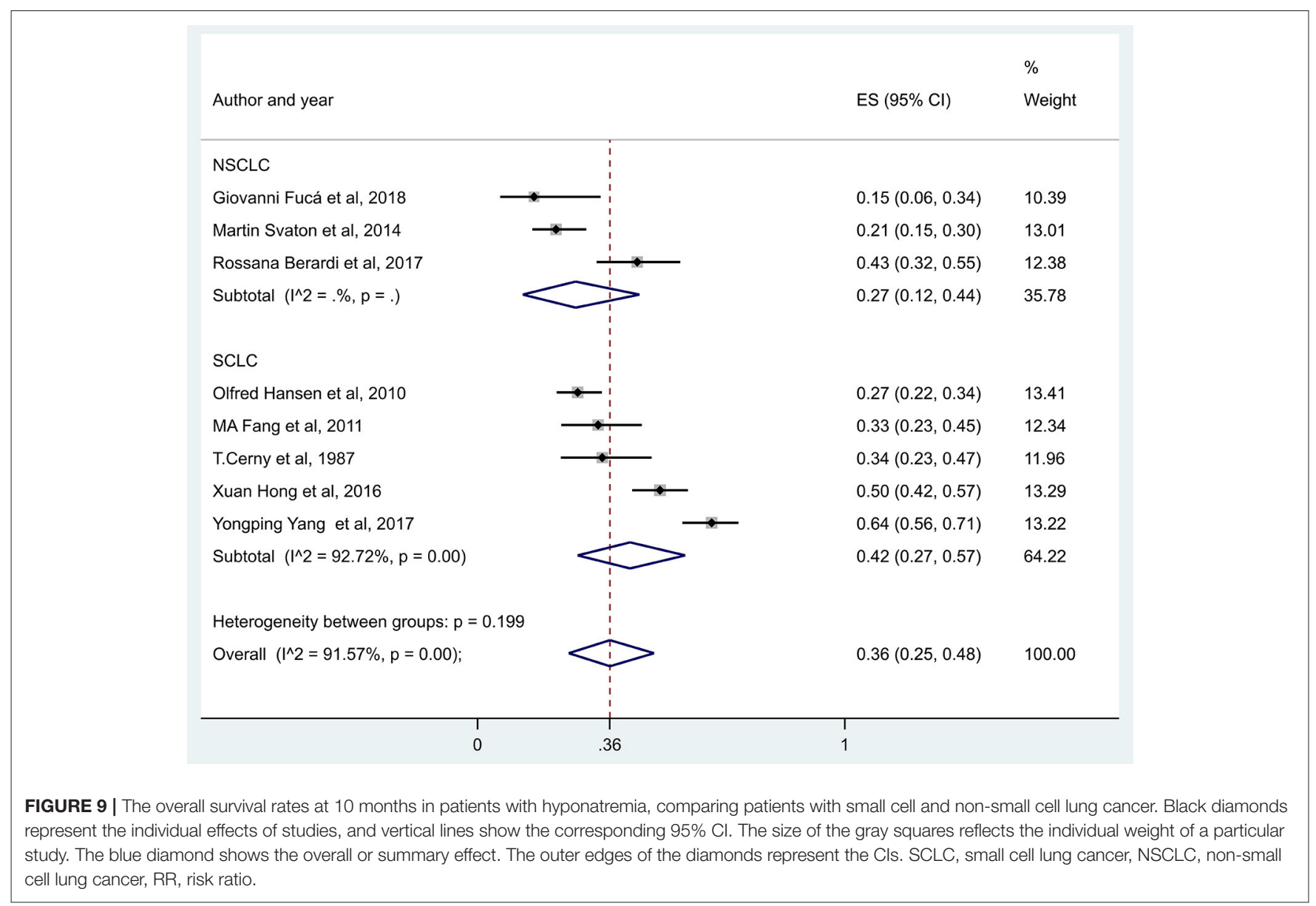

associated with worse overall survival rates in patients with lung cancer.

To the best of our knowledge, this is the first metaanalysis comparing the prognostic significance of pretreatment hyponatremia in patients with NSCLC and SCLC.

According to our analysis, hyponatremia has a more significant negative impact on the overall mortality of patients with NSCLC compared to patients with SCLC, since the overall survival rates at 10 months were significantly lower in patients with hyponatremic NSCLC than in hyponatremic SCLC ones ( $p$ $<0.001)$.

We found only one systematic review in the literature analyzing the independent prognostic role of hyponatremia in lung cancer (19). The authors identified hyponatremia as an independent risk factor in a poor outcome in 6 out of 13 and in 1 out of 3 studies in SCLC and NSCLC, respectively. However, this review has some limitations. In the included studies, hyponatremia was detected both before and during treatment, the overall survival times and rates were only partially available, and the multivariate analysis of hyponatremia was reported only in a few studies (19). In our systematic review, we came to similar conclusions regarding patients with SCLC: overall, out of the 12 studies, six identified hyponatremia as an independent prognostic factor. However, in NSCLC, we found low serum sodium to be a significant independent negative predictor more consistently ( $N=10$ vs. only one paper where it was not).

We also found another meta-analysis similar to ours after updating our systematic search. In contrast to our article, this meta-analysis evaluated the prognostic significance of hyponatremia in patients with NSCLC only, and it did not analyze the prevalence of hyponatremia and its effect on OS rates. In this systematic research, some low-quality studies with a too small number of data on prevalence and prognostic significance were also included; therefore, we chose not to include these articles in our evaluation. Regardless of the differences, their conclusion was similar to ours. They found that hyponatremia is a frequent electrolyte abnormality among patients with NSCLC, and it increases mortality, more pronounced if it remains uncorrected (65).

The improvement of hyponatremia correlated with mortality in retrospective studies in various medical conditions, including lung cancer $(32,66,67)$. However, in some reviews, it was suggested that the impact of hyponatremia correction on mortality should be further investigated because it still seems to be unclear (68-70). In a meta-analysis, including 15 studies with 13,816 patients with hyponatremia, the correction of serum sodium level was achieved in $53.2 \%$ of cases, and 


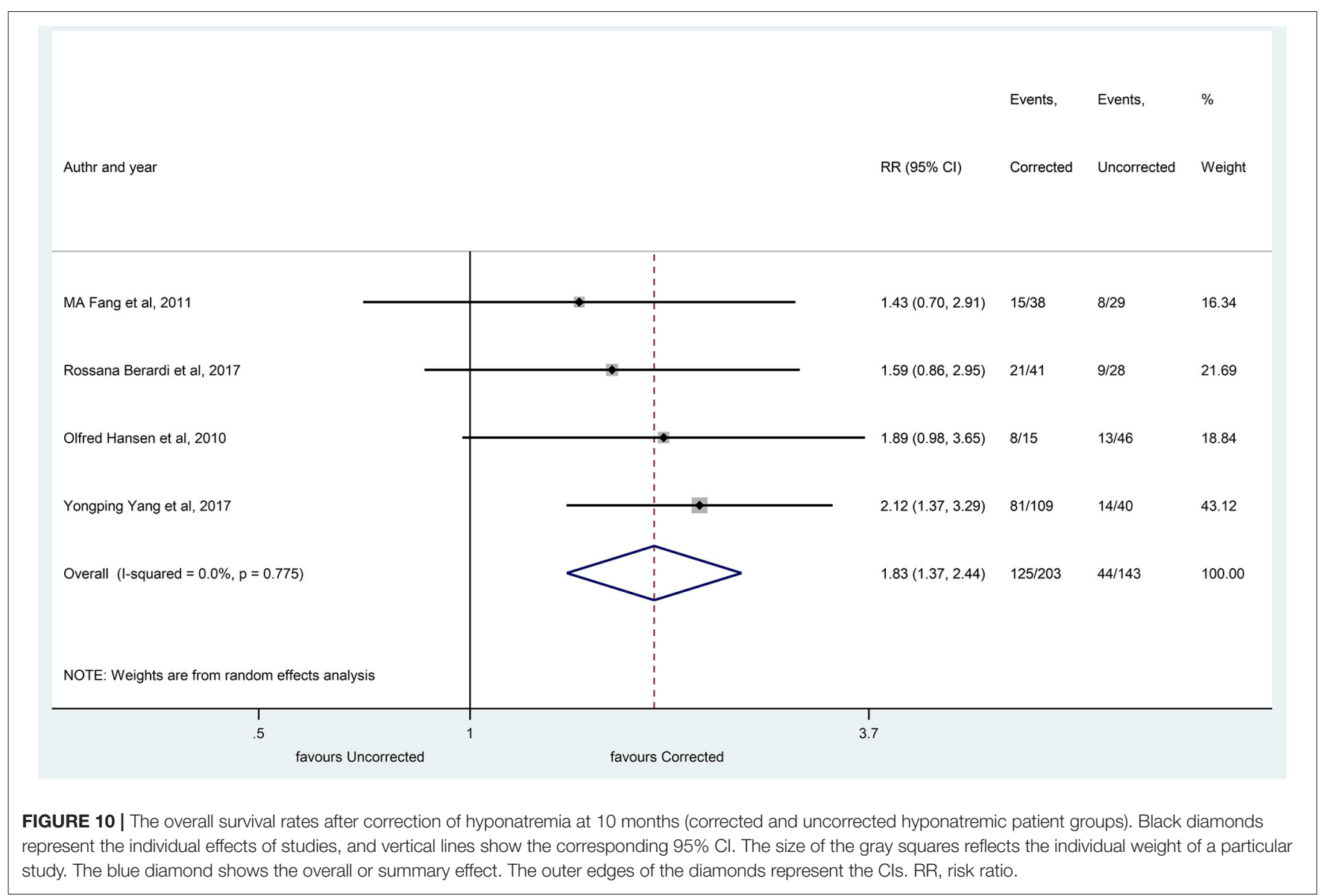

it was associated with a significant reduction in overall mortality (23). Similarly, we found significantly higher OS rates at 10 months among patients with lung cancer if the hyponatremia was ameliorated compared to the uncorrected hyponatremia group. However, when assessed later, at 20 months, this benefit of the treatment was no longer statistically significant, which is in contrast with the observation of the previous meta-analysis carried out in various medical conditions, where reduced mortality could be detected even at 36 months. This discrepancy between the 10- and 20month prognostic data may be related to the higher progression rate of lung cancer and, therefore, a shorter beneficial effect of the correction of the sodium level compared to other (malignant) diseases. However, statistical uncertainties (e.g., discrepant ratios of data available and/or loss of patients to follow-up during the time interval) may also influence this observation. In the meta-analysis of Cantini and colleagues, the risk of electrolyte disorders was evaluated among patients with lung cancer treated with immune checkpoint inhibitors (ICIs). Their conclusion was similar to ours; however, they investigated the incidence of treatment-related hyponatremia among patients with lung cancer. They stated that electrolyte disorders should be monitored frequently and corrected promptly because hyponatremia is associated with a worse prognosis (71).
These results show the importance of the correction of hyponatremia and raise awareness about further therapeutic options in treatment-resistant cases. Numerous papers highlighted the beneficial effect of V2R antagonists (mostly Tolvaptan), with close monitoring of sodium levels in the treatment of patients with hyponatremic lung cancer (72-78). These studies reported effective correction of hyponatremia and improvement of performance status, without any serious adverse events. However, according to our systematic search, in patients with lung cancer, the effect of V2R antagonist treatment on mortality has only been evaluated in one study, which also demonstrated the cost-effectiveness of tolvaptan treatment in Swedish patients with SIADH in pneumonia or SCLC (79). In a review of Fiordoliva et al., they found that SIADH is frequently associated with SCLC, but it should be expected in other lung cancer histotypes as well (12). We plan to investigate the diagnostic and therapeutic approaches of hyponatremia caused by SIADH in patients with lung cancer in the future.

\section{Limitations}

The most significant limitations of our meta-analysis are the following: the lack of randomized controlled trials, the low number of prospective studies, the limited number of studies available in respect of certain relevant questions, the considerable heterogeneity of the included studies, and the variable cut-off 


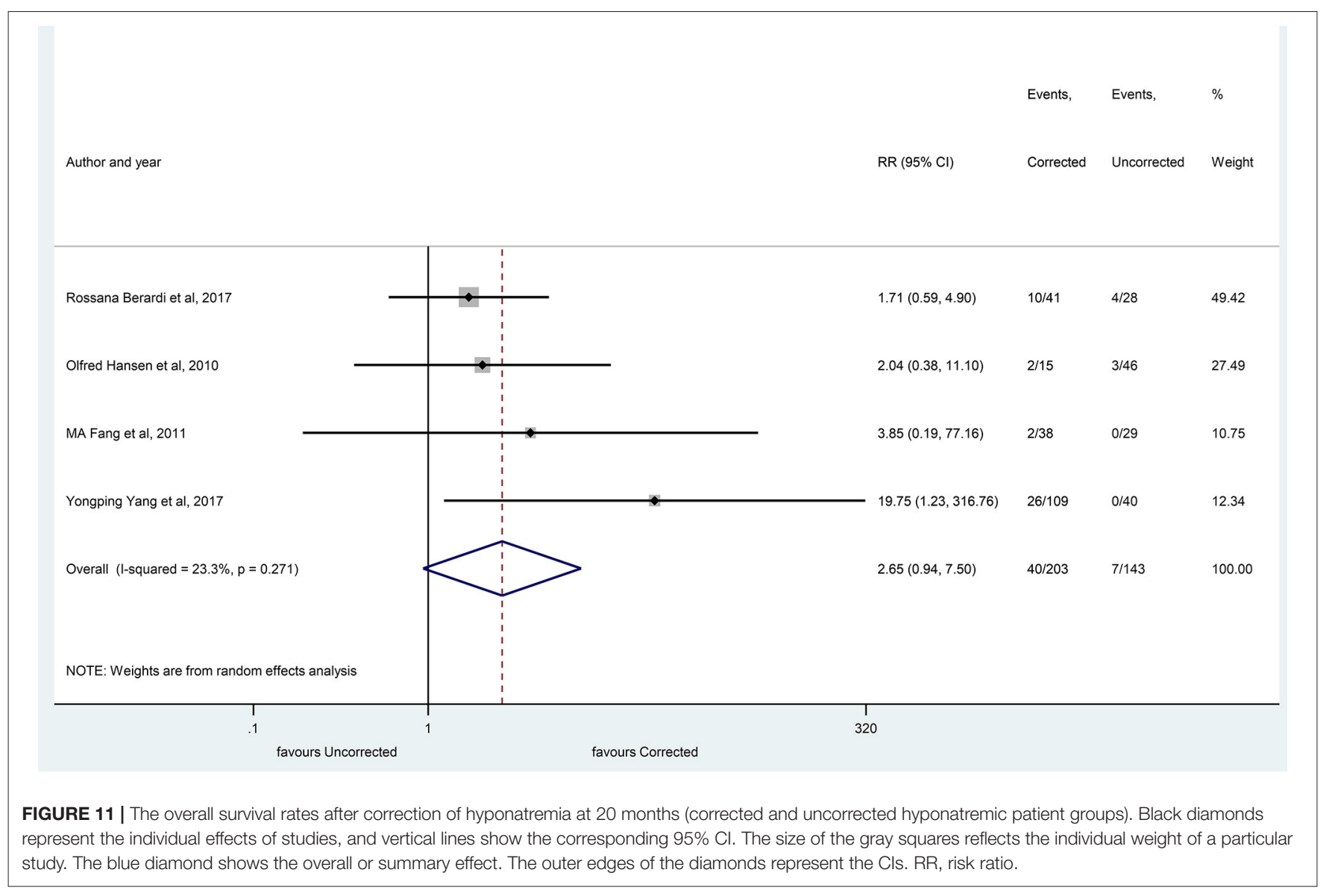

values for serum sodium levels, which all can lead to biased results. The heterogeneity among methods of measuring serum sodium is also a limiting factor. The severity of hyponatremia at the time of diagnosis could potentially have been influenced by some interfering factors, which were not fully evaluated, such as comorbidities and treatments. Also, the lack of randomization between uncorrected and corrected hyponatremia may lead to bias.

From the available data, no certain answer can be given to the question of whether the negative prognostic significance of resistant hyponatremia was due to oncological unresponsiveness or inappropriate sodium correction. Furthermore, incomplete data reporting of follow-up time and loss of the patients to followup, as well as the demographic characteristics of the patients with hyponatremia have also been important limitations, e.g., lack of information about demographic characteristics of patients with hyponatremia may distort the results. More data for a better understanding would be desirable.

\section{CONCLUSIONS}

In the literature, the prevalence of hyponatremia in patients with lung cancer varies between 3 and $94.8 \%$ with a pooled mean frequency of $25 \%$. In our meta-analysis, no significant differences could be observed in the prevalence of hyponatremia among various subgroups, including SCLC vs. NSCLC.

Hyponatremia significantly and negatively influences the overall survival rates of these patients, especially in NSCLC where data are more consistent. Moreover, the improvement of serum sodium levels by specific or symptomatic treatment may improve the survival rates, at least in the short term.

Overall, the contradictions in the literature suggest that betterdesigned studies are necessary to assess the prevalence and prognostic significance of hyponatremia.

\section{DATA AVAILABILITY STATEMENT}

The original contributions presented in the study are included in the article/Supplementary Material, further inquiries can be directed to the corresponding author.

\section{AUTHOR CONTRIBUTIONS}

MG, EB, BT, SK, MF, PH, ZS, EM, and LB: conception and design. EB and MS: administrative support. PH, EM, and LB: provision of study materials or patients. EB and MG: collection and assembly of data. EB, MG, and DN: data analysis and interpretation. MS: manuscript writing. MS: manuscript writing. 
All authors: funding acquisition. All authors read and approved the final manuscript.

\section{FUNDING}

This study was funded by GINOP-2.3.2-15-2016-00048 - STAY ALIVE co-financed by the European Union (European Regional Development Fund) within the framework of Programme Széchenyi 2020 and by the Human Resources Development Operational Programme Grant, Grant Number: EFOP 3.6.2-16-2017-00006 - LIVE LONGER, which is co-financed by the European Union (European Regional

\section{REFERENCES}

1. World Health Organization. Cancer; c2020. Available online at: https://www. who.int/news-room/fact-sheets/detail/cancer (accessed April 7, 2020).

2. World Health Organization. WHO GLOBOCAN; c2018. Cancer Tomorrow. Available online at: https://gco.iarc.fr/tomorrow/graphic-line?type $=0 \&$ type_sex $=0 \&$ mode $=$ population $\&$ sex $=0 \&$ populations $=900 \&$ cancers $=15 \&$ age group $=$ value\&apc_male $=0 \&$ apc $\_$female $=0 \&$ single_unit $=500000 \&$ print $=0$ (accessed April 7, 2020).

3. Bowman BT. Electrolyte disorders associated with cancer. J Onco-Nephrol. (2017) 1:30-5. doi: 10.5301/jo-n.5000004

4. Berardi R, Antonuzzo A, Blasi L, Buosi R, Lorusso V, Migliorino MR, et al. Practical issues for the management of hyponatremia in oncology. Endocrine. (2018) 61:158-64. doi: 10.1007/s12020-018-1547-y

5. Berghmans T, Paesmans M, Body JJ. A prospective study on hyponatraemia in medical cancer patients: epidemiology, aetiology and differential diagnosis. Support Care Cancer. (2000) 8:192-7. doi: 10.1007/s005200050284

6. Sørensen JB, Andersen MK, Hansen HH. Syndrome of inappropriate secretion of antidiuretic hormone (SIADH) in malignant disease. J Intern Med. (1995) 238:97-110. doi: 10.1111/j.1365-2796.1995.tb00907.x

7. Grohé C, Berardi R, Burst V. Hyponatraemia-SIADH in lung cancer diagnostic and treatment algorithms. Crit Rev Oncol Hematol. (2015) 96:18. doi: 10.1016/j.critrevonc.2015.04.005

8. Efthymiou C, Spyratos D, Kontakiotis T. Endocrine paraneoplastic syndromes in lung cancer. Hormones (Athens). (2018) 17:3518. doi: $10.1007 / \mathrm{s} 42000-018-0046-0$

9. Wang X, Liu M, Zhang L, Ma K. Syndrome of inappropriate antidiuretic hormone secretion: a poor prognosis in small-cell lung cancer. Arch Med Res. (2016) 47:19-24. doi: 10.1016/j.arcmed.2015.12.006

10. List AF, Hainsworth JD, Davis BW, Hande KR, Greco FA, Johnson DH. The syndrome of inappropriate secretion of antidiuretic hormone (SIADH) in small-cell lung cancer. J Clin Oncol. (1986) 4:1191-8. doi: 10.1200/JCO.1986.4.8.1191

11. Lokich JJ. The frequency and clinical biology of the ectopic hormone syndromes of small cell carcinoma. Cancer. (1982) 50:21114. doi: 10.1002/1097-0142(19821115)50:10<2111::aid-cncr2820501023>3.0.co;2o

12. Fiordoliva I, Meletani T, Baleani MG, Rinaldi S, Savini A, Di Pietro Paolo M, Berardi R. Managing hyponatremia in lung cancer: latest evidence and clinical implications. Ther Adv Med Oncol. (2017) 9:7119. doi: $10.1177 / 1758834017736210$

13. Dimitriadis GK, Angelousi A, Weickert MO, Randeva HS, Kaltsas G, Grossman A. Paraneoplastic endocrine syndromes. Endocr Relat Cancer. (2017) 24:R173-90. doi: 10.1530/ERC-17-0036

14. Raftopoulos H. Diagnosis and management of hyponatremia in cancer patients. Support Care Cancer. (2007) 15:13417. doi: 10.1007/s00520-007-0309-9

15. Liamis G, Megapanou E, Elisaf M, Milionis H. Hyponatremia-Inducing Drugs. Front Horm Res. (2019) 52:167-77. doi: 10.1159/000493246
Development Fund) within the framework of Programme Széchenyi 2020.

\section{SUPPLEMENTARY MATERIAL}

The Supplementary Material for this article can be found online at: https://www.frontiersin.org/articles/10.3389/fmed. 2021.671951/full\#supplementary-material

Supplementary File 1 | A preferred reporting items for systematic reviews and meta-analyses (PRISMA) checklist.

Supplementary File 2 | A Quality in Prognostic Studies (QUIPS) tool for risk of bias assessment.

16. Oren RM. Hyponatremia in congestive heart failure. Am J Cardiol. (2005) 95(9A):2B-7B. doi: 10.1016/j.amjcard.2005.03.002

17. Ginès P, Guevara M. Hyponatremia in cirrhosis: pathogenesis, clinical significance, and management. Hepatology. (2008) 48:1002-10. doi: 10.1002/hep.22418

18. Peri A. Prognostic and predictive role of hyponatremia in cancer patients. $J$ Cancer Metastasis Treat. (2019) 5:40. doi: 10.20517/2394-4722.2019.14

19. Castillo JJ, Vincent M, Justice E. Diagnosis and management of hyponatremia in cancer patients. Oncologist. (2012) 17:75665. doi: 10.1634/theoncologist.2011-0400

20. Corona G, Giuliani C, Parenti G, Norello D, Verbalis JG, Forti $\mathrm{G}$, et al. Moderate hyponatremia is associated with increased risk of mortality: evidence from a meta-analysis. PLoS ONE. (2013) 8:e80451. doi: 10.1371/journal.pone.0080451

21. Verbalis JG. Managing hyponatremia in patients with syndrome of inappropriate antidiuretic hormone secretion. J Hosp Med. (2010) 5 (Suppl 3):S18-26. doi: 10.1002/jhm.783

22. Harper PG, Souhami RL, Spiro SG, Geddes DM, Guimaraes M, Fearon F, Smyth JF. Tumor size, response rate, and prognosis in small cell carcinoma of the bronchus treated by combination chemotherapy. Cancer Treat Rep. (1982) 66:463-70.

23. Corona G, Giuliani C, Verbalis JG, Forti G, Maggi M, Peri A. Hyponatremia improvement is associated with a reduced risk of mortality: evidence from a meta-analysis. PLoS ONE. (2015) 10:e0124105. doi: 10.1371/journal.pone.0124105

24. Moher D, Liberati A, Tetzlaff J, Altman DG. The PRISMA Group. Preferred reporting items for systematic reviews and meta-analyses: the PRISMA Statement. PLoS Med. (2009) 6:e1000097. doi: 10.1371/journal.pmed.10 00097

25. Hayden JA, Côté P, Bombardier C. Evaluation of the quality of prognosis studies in systematic reviews. Ann Intern Med. (2006) 144:427-37. doi: 10.7326/0003-4819-144-6-200603210-00010

26. Higgins JPT, Thomas J, Chandler J, Cumpston M, Li T, Page MJ, et al. Cochrane Handbook for Systematic Reviews of Interventions. 2nd ed. Chichester: John Wiley \& Sons. (2019). doi: 10.1002/9781119536604

27. Yang Y, Sun N, Sun P, Zhang L. Clinical characteristics and prognosis of elderly small cell lung cancer patients complicated with hyponatremia: a retrospective analysis. Anticancer Res. (2017) 37:4681-6. doi: 10.21873/anticanres.11872

28. Osterlind K, Hansen HH, Dombernowsky P, Hansen M, Andersen PK. Determinants of complete remission induction and maintenance in chemotherapy with or without irradiation of small cell lung cancer. Cancer Res. (1987) 47:2733-6.

29. Zarzecka M, Kubicki P, Kozielski J. Hyponatraemia - evaluation of prevalence in patients hospitalized in the Pulmonary Department and prognostic significance in lung cancer patients. Pneumonol Alergol Pol. (2014) 82:1824. doi: 10.5603/PiAP.2014.0004

30. Hermes A, Waschki B, Reck M. Hyponatremia as prognostic factor in small cell lung cancer-a retrospective single institution analysis. Respir Med. (2012) 106:900-4. doi: 10.1016/j.rmed.2012.02.010 
31. Wang W, Song Z, Zhang Y. Hyponatremia in small cell lung cancer is associated with a poorer prognosis. Transl Cancer Res. (2016) 5:3643. doi: 10.3978/j.issn.2218-676X.2016.01.04

32. Berardi R, Santoni M, Newsom-Davis T, Caramanti M, Rinaldi S, Tiberi $\mathrm{M}$, et al. Hyponatremia normalization as an independent prognostic factor in patients with advanced non-small cell lung cancer treated with first-line therapy. Oncotarget. (2017) 8:23871-9. doi: 10.18632/oncotarget.13372

33. Sengupta A, Banerjee SN, Biswas NM, Jash D, Saha K, Maji A, et al. The incidence of hyponatraemia and its effect on the ECOG performance status among lung cancer patients. J Clin Diagn Res. (2013) 7:167882. doi: 10.7860/JCDR/2013/5900.3225

34. Kobayashi N, Usui S, Yamaoka M, Suzuki H, Kikuchi S, Goto Y, et al. The influence of serum sodium concentration on prognosis in resected non-small cell lung cancer. Thorac Cardiovasc Surg. (2014) 62:33843. doi: 10.1055/s-0033-1359713

35. Fucà G, Galli G, Poggi M, Lo Russo G, Proto C, Imbimbo M, et al. Low baseline serum sodium concentration is associated with poor clinical outcomes in metastatic non-small cell lung cancer patients treated with immunotherapy. Target Oncol. (2018) 13:795-800. doi: 10.1007/s11523-018-0599-5

36. Alamoudi OS. Lung cancer at a University Hospital in Saudi Arabia: a four-year prospective study of clinical, pathological, radiological, bronchoscopic, and biochemical parameters. Ann Thorac Med. (2010) 5:30-6. doi: 10.4103/1817-1737.58957

37. Hansen O, Sørensen P, Hansen KH. The occurrence of hyponatremia in SCLC and the influence on prognosis: a retrospective study of 453 patients treated in a single institution in a 10-year period. Lung Cancer. (2010) 68:111-4. doi: 10.1016/j.lungcan.2009.05.015

38. Svaton M, Fiala O, Pesek M, Bruha F, Mukensnabl P. Racek, et al. Predictive and prognostic significance of sodium levels in patients with NSCLC treated by erlotinib. Anticancer Res. (2014) 34:7461-5.

39. Allan SG, Stewart ME, Love S, Cornbleet MA, Smyth JF, Leonard RC. Prognosis at presentation of small cell carcinoma of the lung. Eur J Cancer. (1990) 26:703-5. doi: 10.1016/0277-5379(90)90121-9

40. Li W, Chen X, Wang L, Wang Y, Huang C, Wang G, et al. The prognostic effects of hyponatremia and hyperchloremia on postoperative NSCLC patients. Curr Probl Cancer. (2019) 43:402-10. doi: 10.1016/j.currproblcancer.2018.12.006

41. Osterlind K, Andersen PK. Prognostic factors in small cell lung cancer: multivariate model based on 778 patients treated with chemotherapy with or without irradiation. Cancer Res. (1986) 46:4189-94.

42. Doshi KH, Shriyan B, Nookala MK, Kannan S, Joshi A, Noronha V, et al. Prognostic significance of pretreatment sodium levels in patients of nonsmall cell lung cancer treated with pemetrexed-platinum doublet chemotherapy. $J$ Cancer Res Ther. (2018) 14:1049-53. doi: 10.4103/0973-1482.187296

43. Johnson BE, Chute JP, Rushin J, Williams J, Le PT, Venzon $\mathrm{D}$, et al. prospective study of patients with lung cancer and hyponatremia of malignancy. Am J Respir Crit Care Med. (1997) 156:1669-78. doi: 10.1164/ajrccm.156.5.96-10075

44. Sagman U, Maki E, Evans WK, Warr D, Shepherd FA, Sculier JP, et al. Smallcell carcinoma of the lung: derivation of a prognostic staging system. J Clin Oncol. (1991) 9:1639-49. doi: 10.1200/JCO.1991.9.9.1639

45. Jacot W, Colinet B, Bertrand D, Lacombe S, Bozonnat MC, Daurès JP, et al. Quality of life and comorbidity score as prognostic determinants in non-small-cell lung cancer patients. Ann Oncol. (2008) 19:145864. doi: 10.1093/annonc/mdn064

46. Hong X, Xu Q, Yang Z, Wang M, Yang F, Gao Y, et al. The value of prognostic factors in Chinese patients with small cell lung cancer: a retrospective study of 999 patients. Clin Respir J. (2018) 12:433-47. doi: 10.1111/crj.12534

47. Maestu I, Pastor M, Gómez-Codina J, Aparicio J, Oltra A, Herranz C, et al. Pretreatment prognostic factors for survival in small-cell lung cancer: a new prognostic index and validation of three known prognostic indices on 341 patients. Ann Oncol. (1997) 8:547-53. doi: 10.1023/A:1008212826956

48. Kawahara M, Fukuoka M, Saijo N, Nishiwaki Y, Ikegami H, Tamura T, et al. Prognostic factors and prognostic staging system for small cell lung cancer. Jpn J Clin Oncol. (1997) 27:158-65. doi: 10.1093/jjco/27.3.158

49. Cerny T, Blair V, Anderson H, Bramwell V, Thatcher N. Pretreatment prognostic factors and scoring system in 407 small-cell lung cancer patients. Int J Cancer. (1987) 39:146-9. doi: 10.1002/ijc.2910390204
50. Ma F, Liu X, Hu C, Huang M. [Clinical features and prognosis analysis of small-cell lung cancer complicated with hyponatremia]. Zhong Nan Da Xue Xue Bao Yi Xue Ban. (2011) 36:647. doi: 10.3969/j.issn.1672-7347.2011.01.010

51. Umemura S, Segawa Y, Ueoka H, Hotta K, Kiura K, Takigawa N, et al. Serum level of arginine-vasopressin influences the prognosis of extensivedisease small-cell lung cancer. J Cancer Res Clin Oncol. (2007) 133:51924. doi: 10.1007/s00432-007-0196-y

52. Jacot W, Quantin X, Boher JM, Andre F, Moreau L, Gainet M, et al Association d'Enseignement et de Recherche des Internes en Oncologie. Brain metastases at the time of presentation of non-small cell lung cancer: a multicentric AERIO analysis of prognostic factors. Br J Cancer. (2001) 84:903-9. bjoc.2000.1706 doi: 10.1054/bjoc.2000.1706

53. Rechnitzer S. Bülzebruck H, Ebert W, Drings P. Pretreatment Prognostic Factors for Survival in Non-Small-Cell Lung Cancer: A Multivariate Analysis of 229 Patients Onkologie. Oncol Res Treat. (1998) 21:20410. doi: $10.1159 / 000026816$

54. Bose CK, Dey S, Mukhopadhyay A. Hyponatremia of non-small cell lung cancer: Indian experience. Indian J Med Paediatr Oncol. (2011) 32:139142. doi: 10.4103/0971-5851.92810

55. Rinaldi S, Santoni M, Leoni G, Fiordoliva I, Marcantognini G, Meletani T, et al. The prognostic and predictive role of hyponatremia in patients with advanced non-small cell lung cancer (NSCLC) with bone metastases. Support Care Cancer. (2019) 27:1255-61. doi: 10.1007/s00520-018-4489-2

56. Chan VWQ, Henry MT, Kennedy MP. Hyponatremia and hypercalcemia: a study of a large cohort of patients with lung cancer. Transl Cancer Res. (2020) 9:222-30. doi: 10.21037/tcr.2019.12.72

57. Huang LL, Hu XS, Wang Y, Li JL, Wang HY, Liu P, et al. Survival and pretreatment prognostic factors for extensive-stage small cell lung cancer: a comprehensive analysis of 358 patients. Thorac Cancer. (2021) 12:194351. doi: 10.1111/1759-7714.13977

58. Upadhyay A, Jaber BL, Madias NE. Incidence and prevalence of hyponatremia. Am J Med. (2006) 119 (7 Suppl 1):S305. doi: 10.1016/j.amjmed.2006.05.005

59. Peri A. Management of hyponatremia: causes, clinical aspects, differential diagnosis and treatment. Expert Rev Endocrinol Metab. (2019) 14:1321. doi: 10.1080/17446651.2019.1556095

60. Hawkins RC. Age and gender as risk factors for hyponatremia and hypernatremia. Clin Chim Acta. (2003) 337 (1-2):16972. doi: 10.1016/j.cccn.2003.08.001

61. Mohan S, Gu S, Parikh A, Radhakrishnan J. Prevalence of hyponatremia and association with mortality: results from NHANES. Am J Med. (2013) 126:1127-37.e1. doi: 10.1016/j.amjmed.2013.07.021

62. Sterns RH, Silver SM. Complications and management of hyponatremia. Curr Opin Nephrol Hypertens. (2016) 25:114119. doi: 10.1097/MNH.0000000000000200

63. Verbalis JG, Goldsmith SR, Greenberg A, Korzelius C, Schrier RW, Sterns RH, et al. Diagnosis, evaluation, and treatment of hyponatremia: expert panel recommendations. Am J Med. (2013) 126 (10 Suppl 1):S142. doi: 10.1016/j.amjmed.2013.07.006

64. Kraft MD, Btaiche IF, Sacks GS, Kudsk KA. Treatment of electrolyte disorders in adult patients in the intensive care unit. Am J Health Syst Pharm. (2005) 62:1663-82. doi: 10.2146/ajhp040300

65. Sandfeld-Paulsen B, Aggerholm-Pedersen N, Winther-Larsen A Hyponatremia as a prognostic factor in non-small cell lung cancer: a systematic review and meta-analysis. Transl Lung Cancer Res. (2021) 10:651-61. doi: 10.21037/tlcr-20-877

66. Petereit $\mathrm{C}$, Zaba $\mathrm{O}$, Teber I, Grohé C. Ist die Hyponatriämie $(\mathrm{HN})$ ein Prognosefaktor für das Gesamtüberleben der Patienten mit Lungenkarzinom? [Is hyponatremia a prognostic marker of survival for lung cancer?]. Pneumologie. (2011) 65:565-71. doi: 10.1055/s-0030-1256668

67. Balachandran K, Okines A, Gunapala R, Morganstein D, Popat S. Resolution of severe hyponatraemia is associated with improved survival in patients with cancer. BMC Cancer. (2015) 15:163. doi: 10.1186/s12885-0151156-6

68. Sun L, Hou Y, Xiao Q, Du Y. Association of serum sodium and risk of allcause mortality in patients with chronic kidney disease: a meta-analysis and sysematic review. Sci Rep. (2017) 7:15949. doi: 10.1038/s41598-017-16242-3 
69. Hoorn EJ, Zietse R. Diagnosis and treatment of hyponatremia: compilation of the guidelines. J Am Soc Nephrol. (2017) 28:1340-9. doi: 10.1681/ASN.2016101139

70. Rusinaru D, Tribouilloy C, Berry C, Richards AM, Whalley GA, Earle N, et al. Relationship of serum sodium concentration to mortality in a wide spectrum of heart failure patients with preserved and with reduced ejection fraction: an individual patient data meta-analysis $\left({ }^{\dagger}\right)$ : Meta-Analysis Global Group in Chronic heart failure (MAGGIC). Eur J Heart Fail. (2012) 14:113946. doi: 10.1093/eurjhf/hfs099

71. Cantini L, Merloni F, Rinaldi S, Lenci E, Marcantognini G, Meletani $\mathrm{T}$, et al. Electrolyte disorders in advanced non-small cell lung cancer patients treated with immune check-point inhibitors: a systematic review and meta-analysis. Crit Rev Oncol Hematol. (2020) 151:102974. doi: 10.1016/j.critrevonc.2020.102974

72. Dixon MB, Lien YH. Tolvaptan and its potential in the treatment of hyponatremia. Ther Clin Risk Manag. (2008) 4:1149-1155. doi: 10.2147/TCRM.S3115

73. Thajudeen B, Salahudeen AK. Role of tolvaptan in the management of hyponatremia in patients with lung and other cancers: current data and future perspectives. Cancer Manag Res. (2016) 8:105-114. doi: 10.2147/CMAR.S90169

74. Fraser IM, Brooke AM, Dorey NE, Toy EW. Use of tolvaptan, a new V2 receptor antagonist, in the treatment of syndrome of inappropriate antidiuretic hormone secretion (SIADH) secondary to small cell lung cancer (SCLC) - a case series. Lung Cancer. (2014) 83:S69. doi: 10.1016/S0169-5002(14)70187-4

75. Petereit C, Zaba O, Teber I, Lüders H, Grohé C. A rapid and efficient way to manage hyponatremia in patients with SIADH and small cell lung cancer: treatment with tolvaptan. BMC Pulm Med. (2013) 13:55. doi: 10.1186/1471-2466-13-55

76. Li-Ng M, Verbalis JG. Conivaptan: evidence supporting its therapeutic use in hyponatremia. Core Evid. (2010) 4:83-92. doi: 10.2147/CE.S5997
77. Zeltser D, Rosansky S, van Rensburg H, Verbalis JG, Smith N, Conivaptan Study Group. Assessment of the efficacy and safety of intravenous conivaptan in euvolemic and hypervolemic hyponatremia. Am J Nephrol. (2007) 27:447457. doi: 10.1159/000106456

78. Annane D, Decaux G, Smith N, Conivaptan Study Group. Efficacy and safety of oral conivaptan, a vasopressin-receptor antagonist, evaluated in a randomized, controlled trial in patients with euvolemic or hypervolemic hyponatremia. Am J Med Sci. (2009) 337:28-36. doi: 10.1097/MAJ.0b013e31817b8148

79. Jamookeeah C, Robinson P, O’Reilly K, Lundberg J, Gisby M, Ländin M, et al. Cost-effectiveness of tolvaptan for the treatment of hyponatraemia secondary to syndrome of inappropriate antidiuretic hormone secretion in Sweden. BMC Endocr Disord. (2016) 16:22. doi: 10.1186/s12902-016-0104-Z

Conflict of Interest: The authors declare that the research was conducted in the absence of any commercial or financial relationships that could be construed as a potential conflict of interest.

Publisher's Note: All claims expressed in this article are solely those of the authors and do not necessarily represent those of their affiliated organizations, or those of the publisher, the editors and the reviewers. Any product that may be evaluated in this article, or claim that may be made by its manufacturer, is not guaranteed or endorsed by the publisher.

Copyright (C) 2021 Bartalis, Gergics, Tinusz, Földi, Kiss, Németh, Solymár, Szakács, Hegyi, Mezösi and Bajnok. This is an open-access article distributed under the terms of the Creative Commons Attribution License (CC BY). The use, distribution or reproduction in other forums is permitted, provided the original author(s) and the copyright owner(s) are credited and that the original publication in this journal is cited, in accordance with accepted academic practice. No use, distribution or reproduction is permitted which does not comply with these terms. 